\title{
Experimental Study of Volumetric Fracturing Properties for Shale under Different Stress States
}

\author{
Hongjian Wang, ${ }^{1,2}$ Jin Li, ${ }^{1}$ Fei Zhao $\mathbb{D}^{1},{ }^{1}$ Jinyu Dong, ${ }^{1}$ Yanzong Cui, ${ }^{1}$ and Wanlin Gong ${ }^{1}$ \\ ${ }^{1}$ North China University of Water Resources and Electric Power, Zhengzhou, 450045 Henan, China \\ ${ }^{2}$ Sinopec Zhongyuan Oilfield Branch, Puyang, 457001 Henan, China \\ Correspondence should be addressed to Fei Zhao; zhaofei@ncwu.edu.cn
}

Received 3 January 2021; Revised 5 February 2021; Accepted 16 February 2021; Published 11 March 2021

Academic Editor: Feng Xiong

Copyright (C) 2021 Hongjian Wang et al. This is an open access article distributed under the Creative Commons Attribution License, which permits unrestricted use, distribution, and reproduction in any medium, provided the original work is properly cited.

\begin{abstract}
Shale gas can be commercially produced using the stimulated reservoir volume (SRV) with multistage fracturing or multiwell synchronous fracturing. These fracturing technologies can produce additional stress fields that significantly influence the crack initiation pressure and the formation of an effective fracture network. Therefore, this study primarily investigated the evolution of crack initiation and propagation in a hydraulic rock mass under various stress conditions. Combining the in situ stress characteristics of a shale reservoir and fracturing technology, three types of true triaxial volumetric fracturing simulation experiments were designed and performed on shale, including three-dimensional constant loading, one-dimensional pressurization disturbance, and one-dimensional depressurization disturbance. The results indicate that the critical failure strength of the shale rock increases as the three-dimensional constant loads are increased. The rupture surface is always parallel to the maximum principal stress plane in both the simulated vertical and horizontal wells. Under the same in situ stress conditions in the wellbore direction, if the lateral pressure becomes larger, the critical failure strength of shale rock would increase. Additionally, when the lateral in situ stress difference coefficient is smaller, the rock specimen has an evident trend to form more complex cracks. When the shale rock was subjected to lateral disturbance loads, the critical failure strength was approximately $10 \mathrm{MPa}$ less than that in the state of constant loading, indicating that the specimen with disturbance loads is more likely to be fractured. Moreover, shale rock under the depressurization disturbance load is more easily fractured compared with the pressurization disturbance. These findings could provide a theoretical basis and technical support for multistage or multiwell synchronous fracturing in shale gas production.
\end{abstract}

\section{Introduction}

Shale gas, an important supplement to conventional energy resources, has been paid considerable attention in recent years $[1,2]$. The total production of shale gas has reached about 180 billion cubic meters, about $34 \%$ of total natural gas output of US, since the shale gas revolution occurred in 1982. The key factor owing such great success of the United States is the mastery of large-scale volumetric fracturing technique for ultralow permeability shale reservoirs $[3,4]$.

In conventional reservoirs and tight gas sands, singleplane fracture half-length and conductivity are the key drivers for stimulation performance. In shale reservoirs, where complex network structures in multiple planes are created, the concept of a single fracture half-length and conduc- tivity is insufficient to describe stimulation performance [5]. It is very important to study the mechanical properties and influencing factors of rock materials [6-10]. However, there are few articles on shale fracture laws and influencing factors $[11,12]$. The works of Fisher $(2002,2004)$ and Maxwell (2002) were the first papers to discuss the creation of large fracture networks in the Barnett shale and show initial relationships between treatment size, network size and shape, and production response [13-15]. Microseismic fracture mapping results indicated that the fracture network size was related to the stimulation treatment volume. Mayerhofer et al. (2010) first proposed the concept of stimulated reservoir volume (SRV for short) during the research on microseismic techniques and fracture changes of Barnett shale rock [16]. The new theory of volumetric fracturing is put forward 
basing on volumetric reconstruction and refers to the crossed network formation of natural crack and artificial crack, which is caused by the expansion of natural crack and brittle rock shear slip during hydraulic fracturing process. Hence, the modification volume is increased and then the initial production and ultimate recovery factor can be enhanced. Hydraulic fracturing by SRV is a major technology to achieve commercial development of shale gas [17]. However, volumetric fracturing of shale reservoir is mainly affected by internal control factors and external control factors [18]. The shale reservoir qualities are the internal control factors affecting the formation of volumetric fracturing network, mainly including rock mineralogical characteristics and physical and mechanical properties as well as rock sensitivities. Those shales with high brittle mineral content, high Young's modulus, and lower Poisson's ratio and sensitivity have better fracturing properties and can be called as sweet spot for shale gas well [19-22]. The geological environment of shale reservoirs and optimized fracturing measures are important guarantees and key external factors for the volumetric fracturing network formation and its full growth, and they directly control the pattern and scale of hydraulic crack [23]. The study of the geologic background such as horizontal principal stress difference and the relationship between natural crack and hydraulic crack can help us to realize the hydraulic crack propagation along the natural crack direction and the transformation into complex fracture network; thus, the stimulated reservoir volume can be improved largely $[24,25]$. In addition, the morphology of fracture network can also be affected by the fracturing operation factors (volume of fracturing fluid, flow rate, and the spacing between fracturing segments) [26] and fracturing techniques (horizontal well multistage fracturing, synchronous fracturing, zipper fracturing, and refracturing) [27].

Horizontal well multistage fracturing, synchronous fracturing, and pulse fracturing are new technologies for effective shale reservoir reconstruction. These technologies are used by applying stress perturbation during the reservoir fracturing process to change the in situ stress environment to control the formation and orientation of the cracks. Then, the effective 3D (three-dimensional) fracture network can be created $[28,29]$. However, these novel technologies are only in preliminary stage. Researchers recently focused on the study of synergistic effect of stress field in fracturing reservoirs [30], density and surface area calculation of fracture network [31], and mechanical conditions of net cracks formation [32] and so on. The above research indicates that disturbance loading significantly impacts effective reservoir reconstruction. Moreover, many researchers have experimentally analyzed the influencing factors of volumetric fracturing. For example, Cai et al. (2019) proposed a new method of multitimes pulse $\mathrm{SC}-\mathrm{CO}_{2}$ jet fracturing [33]. The results demonstrated that there are more initiation positions and complex fracture networks after pulse $\mathrm{SC}-\mathrm{CO}_{2}$ jet fracturing due to substantial impingement and pressurization. To better understand the nonplanar propagation and geometry of fracture networks, Heng et al. (2019) utilized the true triaxial hydraulic fracturing simulation test system to study the evolution of fracturing networks in layered shale rock [34]. The results revealed that the typical significant fluctuation in the injection pressure, which is closely related to the growth of subfractures along the bedding planes or natural fractures, is a distinct characteristic of nonplanar propagation of hydraulic fractures. Hou et al. (2018) conducted a series of large-scale true triaxial experiments with acoustic emission (AE) monitoring to characterize the fracture initiation and propagation in selected deep shale formations [35]. They found that the difficulty in the complex fracture network formation was from the high contrast in stress that was controlling the fracture propagation path, generating large primary fractures instead of activating discontinuities. However, during the process of multiwell or multistage fracturing reconstruction, stress shadows could occur, leading to stress cancellation, which prevents crack extension and can partially reduce the fracturing volume of the reservoirs $[36,37]$. Therefore, it is necessary to design a rational multiwell or multistage fracturing scheme to avoid the adverse effects of an additional perturbation stress field on the fracturing results.

Hence, the causes of the formation of perturbation stress fields and geological effects, as well as fracture characteristics of the shale rock under perturbation loading, should be explored and are the critical points of mastering the 3D fracturing crack network formation. In this study, hydraulic fracturing simulation experiments were conducted to evaluate different stress paths, combining the in situ features of the shale reservoir and hydraulic fracturing technology. Therefore, the experimental results could lead to a better understanding of rock crack initiation and propagation and provide the theoretical basis and technical support for multiwell or multistage shale gas development.

\section{Test Apparatus and Sample Preparation}

2.1. Test Apparatus. Volumetric fracturing in a deep reservoir is a complex physical and mechanical process. Laboratory simulation test of volumetric fracturing is a crucial method to recognize the mechanism of crack initiation and propagation. The actual physical and mechanical process of crack initiation and propagation can be directly observed using these tests by simulating the actual formation conditions. Additionally, the various factors that influence crack initiation and propagation can be separated and analyzed individually to determine which factors are the most significant $[38,39]$.

In this study, a large true triaxial hydraulic fracturing simulation was used to perform volumetric fracturing tests on natural shale rock under perturbation loading. The experiment apparatuses included the large true triaxial steel frame, MTS servo pressure pump, stabilized voltage supply, oil and water separator, and other auxiliary devices, as shown in Figure 1 [40]. The test system provided a rigid load using the hoisting jack with the maximum pressure of $60 \mathrm{MPa}$ to the lateral surface of the specimen. The MTS servo pressure pump and oil-water separator were used to inject highpressure fluids into the wellbore pump to simulate the hydraulic fracturing process. When we began to pump the fracturing fluid, the data acquisition system simultaneously recorded the pump pressure, discharge, and other 


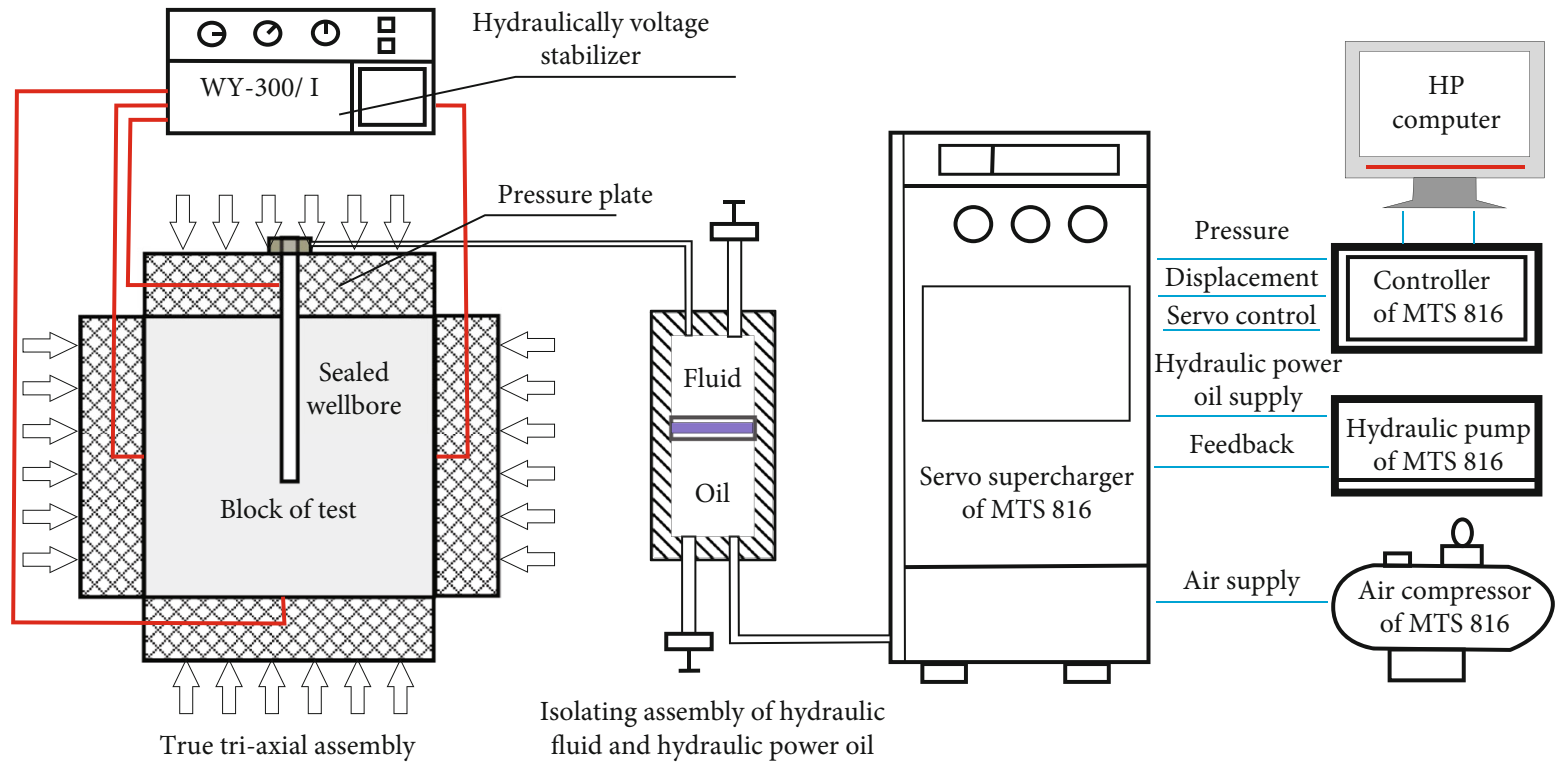

Figure 1: True triaxial volumetric fracing test system.

parameters, and the crack formation after the specimen rupture was observed.

2.2. Sample Preparation. Specimens used in the volumetric fracturing experiment were natural shales that were enclosed with concrete. The shale rock samples were collected from outcrops of the Lower Silurian Longmaxi Formation in the Sichuan Basin, China. These shale rock samples were cut into $200 \mathrm{~mm} \times 200 \mathrm{~mm} \times 200 \mathrm{~mm}$ cubes and then naturally airdried, with the requirement that the nonparallelism of the specimen's end surfaces was less than $0.01 \mathrm{~mm}$. The basic dimensions of the tested specimen were $300 \mathrm{~mm} \times 300 \mathrm{~mm}$ $\times 300 \mathrm{~mm}$ with the concrete cast on the outside of the cubic shale specimen. The concrete parameters could be determined using the similarity criteria and index. Ordinary Portland cement and anhydrous sodium sulfate were mixed with the quartz sand for high-performance concrete to improve the early strength and reduce the curing time [41]. The cement was mixed with quartz sand with the ratio of one is to one, whereas the ratio of the mixed materials and water was two is to five. The specimen preparation can be briefly summarized as follows. (1) The shale rock specimen was placed in the middle of the mold, and then the mixed concrete was poured slowly around the specimen. (2) The mold was filled with concrete, and then the apparatus was leveled and repeatedly impacted until no bubbles emerged from the mixed material. (3) Then, the casting specimen was allowed to cure for two weeks to strengthen the concrete. (4) Finally, the specimen's surface was polished to avoid stress concentration during the loading process. $\mathrm{AB}$ glue was used to seal the gap of the wellbore (see Figure 2).

\section{Experiment Design and Procedures}

3.1. Experiment Design. The mechanical tests performed in the laboratory determined that the shale rock of Longmaxi Formation had a uniaxial compressive strength of
109.5 MPa, a tensile strength of $6.05 \mathrm{MPa}$, an elastic modulus of 19.2 GPa, and Poisson's ratio of 0.28. Figures 3 and 4 present the uniaxial compression test and the Brazilian splitting test, respectively, which were photographed in the laboratory. The simulated wellbore had a length of $120 \mathrm{~mm}$, a diameter of $10 \mathrm{~mm}$, and an open hole section length of $30 \mathrm{~mm}$. The experiment was designed to investigate the effects of the vertical stress, horizontal stress, in situ stress difference coefficient (SDC), pressurization disturbance, and depressurization disturbance on the crack propagating rules in the fracturing process of vertical or horizontal shale wells, as shown in Table 1.

\subsection{Experiment Procedures}

3.2.1. The First Tested Group. The first test group included specimens \#A-1 and \#A-2 to mimic the fracturing process of a vertical well. The true triaxial volumetric fracturing test with a three-directional constant load was carried out on specimen \#A-1. The three-directional stresses were set as the vertical principal stress $\sigma_{\mathrm{v}}$ of $14 \mathrm{MPa}$, the maximum horizontal principal stress $\sigma_{\mathrm{H}}$ of $3 \mathrm{MPa}$, and the minimum horizontal principal stress $\sigma_{\mathrm{h}}$ of $2 \mathrm{MPa}$. Then, the fracturing fluid was injected into the wellbore at the following rates. The initial rate was $0.1 \mathrm{~mm} / \mathrm{s}$ for approximately $2 \mathrm{~min}$, decreased to $0.02 \mathrm{~mm} / \mathrm{s}$ during the fracturing stage, and further reduced to $0.001 \mathrm{~mm} / \mathrm{s}$ during the wellbore pressure stabilization stage. Finally, the injection rate was changed to $0.05 \mathrm{~mm} / \mathrm{s}$ after the crack coalescence until the rock specimen's final disruption. Diameter of fracturing pump $R=12$ $\mathrm{cm}$, section area $A=113 \mathrm{~cm}^{2}$, and the initial pumping rate was $1.13 \mathrm{ml} / \mathrm{s}$ for approximately $2 \mathrm{~min}$, decreased to $0.226 \mathrm{ml} / \mathrm{s}$ during the fracturing stage, and further reduced to $0.0113 \mathrm{ml} / \mathrm{s}$ during the wellbore pressure stabilization stage. Finally, the injection rate was changed to $0.565 \mathrm{ml} / \mathrm{s}$ after the crack coalescence until the rock specimen's final disruption. The experimental data, including the crack initiation 


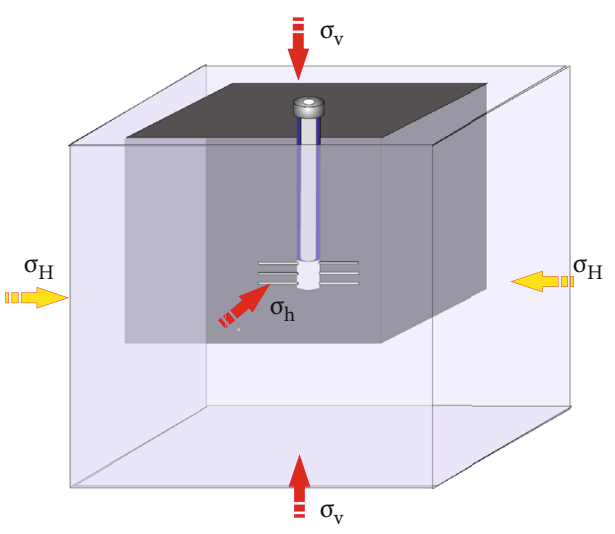

(a) Sketch map of rock specimen

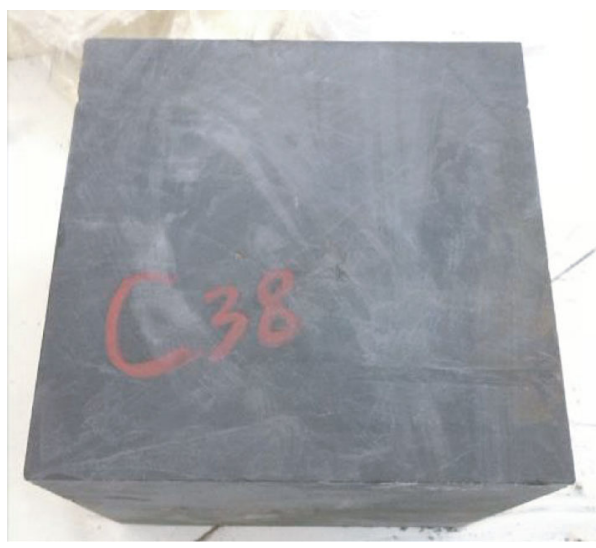

(c) Shale sample

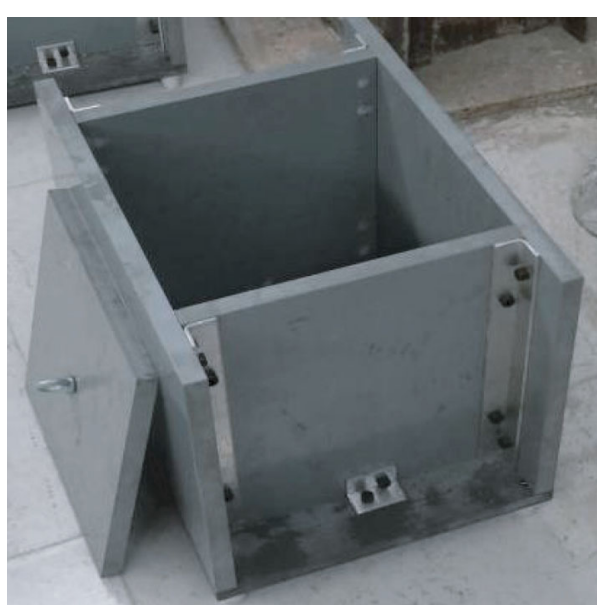

(b) Mould set

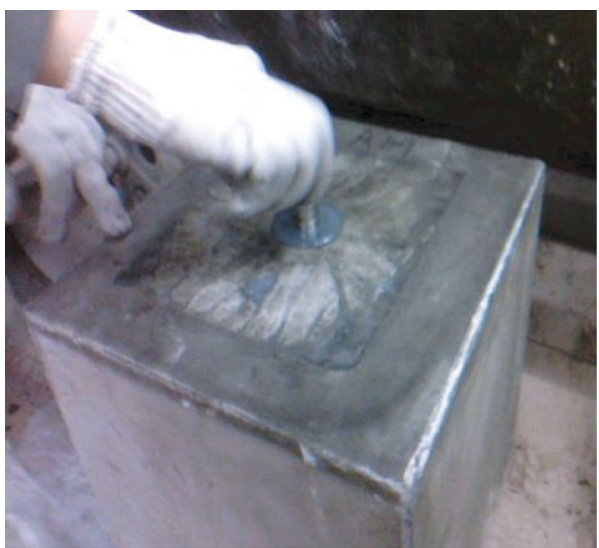

(d) Well cementation

FIGURE 2: Schematic of the rock specimen preparation.

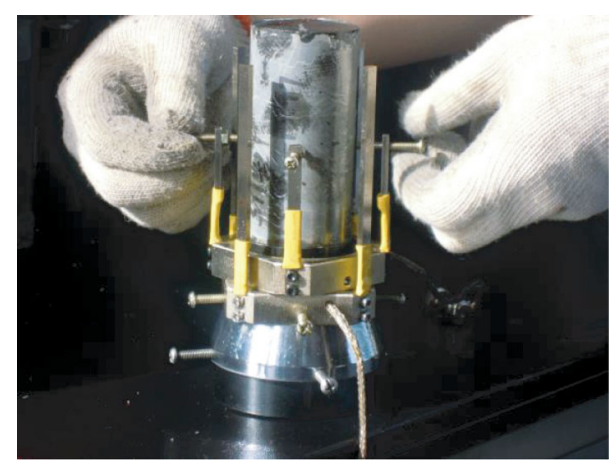

FIgURE 3: Uniaxial compression test of shale rock.

stress $P_{\mathrm{i}}$, critical failure stress $P_{\mathrm{f}}$, crack coalescence stress $P_{\mathrm{c}}$, crack initiation time $T_{\mathrm{i}}$, critical failure time $T_{\mathrm{f}}$, and crack coalescence time $T_{c}$, were all recorded and combined to analyze the fracture characteristics.

The true triaxial volumetric fracturing test under oneway pressurization disturbance was performed on specimen \#A-2. The experimental procedures are as follows. (1) The three principal directional stresses were set to the initial values. (2) The wellbore pressure was maintained at a $P$ of
$5 \mathrm{MPa}$, and the initial stresses were set as the minimum horizontal principal stress $\sigma_{\mathrm{h}}$ of $2 \mathrm{MPa}$ and the vertical stress $\sigma_{\mathrm{v}}$ of $14 \mathrm{MPa}$. The maximum principal stress $\sigma_{\mathrm{h}}$ was progressively increased to $12 \mathrm{MPa}$ at increments of $3 \mathrm{MPa}$ and intervals of $3 \mathrm{~min}$. If the specimen is ruptured, the test was concluded. (3) If not, the wellbore pressure $P$ was increased to $10 \mathrm{MPa}$. Meanwhile, the maximum principal stress $\sigma_{\mathrm{H}}$ was first suddenly dropped to $3 \mathrm{MPa}$ and then loaded progressively to $12 \mathrm{MPa}$ again at increments of $3 \mathrm{MPa}$ and intervals of $3 \mathrm{~min}$, and the test was stopped if the specimen had ruptured. (4) If not, the wellbore pressure $P$ was increased to $15 \mathrm{MPa}$. Meanwhile, the maximum principal stress $\sigma_{\mathrm{H}}$ was again dropped to $3 \mathrm{MPa}$ and then loaded progressively to $12 \mathrm{MPa}$ again at increments of $3 \mathrm{MPa}$ and intervals of 3 min, stopping if the specimen had ruptured.

In each repeated step, the increment of the wellbore pressure $\Delta P$ was set as $5 \mathrm{MPa}$. This process of pressurization and depressurization was repeated until the specimen had ruptured. The design of the true triaxial volumetric fracturing test with pressurization disturbance is presented in Figure 5. Figure 5(a) is the sketch map of the fracturing model for a vertical well, and Figure 5(b) displays the loading paths, where the black line indicates the vertical principal stress $\sigma_{\mathrm{v}}$, the blue line indicates the maximum horizontal 


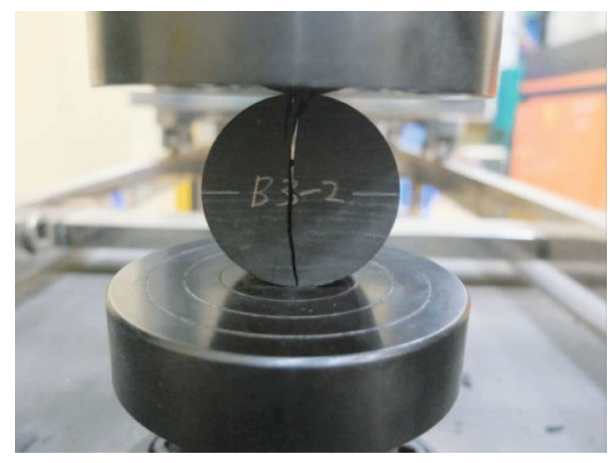

Figure 4: Brazilian splitting test of shale rock.

principal stress $\sigma_{\mathrm{H}}$, the red line indicates the wellbore pressure $P_{\mathrm{w}}$, and the green line indicates the minimum horizontal principal stress $\sigma_{\mathrm{v}}$.

3.2.2. The Second Tested Group. The second test group included specimens $\# \mathrm{~B}-1$ and $\# \mathrm{~B}-2$ to mimic the fracturing process of a horizontal well. The true triaxial volumetric fracturing test with a three-directional constant load was carried out on specimen \#B-1. The three-directional stresses were set as the vertical principal stress $\sigma_{\mathrm{v}}$ of $14 \mathrm{MPa}$, the maximum horizontal principal stress $\sigma_{\mathrm{H}}$ of $3 \mathrm{MPa}$, and the minimum horizontal principal stress $\sigma_{\mathrm{h}}$ of $2 \mathrm{MPa}$. The true triaxial volumetric fracturing test under one-way pressurization disturbance was conducted on specimen \#B-2. The threedirectional stresses were also set as $\sigma_{\mathrm{v}}, \sigma_{\mathrm{H}}$, and $\sigma_{\mathrm{h}}$ were set as 14,3 , and $2 \mathrm{MPa}$, respectively. The testing parameters and procedures were similar to the first group test. The only difference is the arrangement of the wellbore direction. Figure 6(a) shows the sketch map of the fracturing model for the horizontal well, and Figure 6(b) illustrates the loading path design for the true triaxial volumetric fracturing test with one-way pressurization disturbance.

3.2.3. The Third Tested Group. The third test group included specimens \#C-1 and \#C-2 to simulate the fracturing process of a horizontal well. Similarly, the initial stresses $\sigma_{\mathrm{v}}, \sigma_{\mathrm{H}}$, and $\sigma_{\mathrm{h}}$ were set as 14,12 , and $2 \mathrm{MPa}$, respectively, for specimen $\# \mathrm{C}$ - 1 in the volumetric fracturing test under the threedirectional constant loads. The true triaxial volumetric fracturing test under one-way depressurization disturbance was conducted on specimen $\# \mathrm{C}-2$, and the three-directional stresses were also set as $\sigma_{\mathrm{v}}, \sigma_{\mathrm{H}}$, and $\sigma_{\mathrm{h}}$ were set as 14,12 , and $2 \mathrm{MPa}$. The loading steps are as follows. (1) The predefined initial values for $\sigma_{\mathrm{v}}, \sigma_{\mathrm{H}}$, and $\sigma_{\mathrm{h}}$ were set to 14,12 , and $2 \mathrm{MPa}$, respectively. (2) The wellbore pressure $P_{\mathrm{w}}$ was maintained at $5 \mathrm{MPa}$, the minimum horizontal principal stress $\sigma_{\mathrm{h}}$ was $2 \mathrm{MPa}$, and the vertical stress $\sigma_{\mathrm{v}}$ was $14 \mathrm{MPa}$, while decreasing $\sigma_{\mathrm{H}}$ from $12 \mathrm{MPa}$ to $3 \mathrm{MPa}$ at increments of $3 \mathrm{MPa}$ and intervals of $3 \mathrm{~min}$. The rock specimen's surface was observed, and if it experienced the final rupture, then the test was concluded. (3) However, if the rock specimen did not fail, the wellbore pressure $P_{\mathrm{w}}$ was increased to $10 \mathrm{MPa}$, while the values of $\sigma_{\mathrm{v}}$ and $\sigma_{\mathrm{h}}$ were held constant. Meanwhile, $\sigma_{\mathrm{H}}$ would be increased suddenly to $12 \mathrm{MPa}$ and then unloaded progressively to $3 \mathrm{MPa}$ with the same inter- vals, and the test was concluded if the specimen had ruptured. (4) If the rock specimen still had not failed, the wellbore pressure $P_{\mathrm{w}}$ was increased to $15 \mathrm{MPa}$. Meanwhile, $\sigma_{\mathrm{H}}$ would be increased suddenly to $12 \mathrm{MPa}$ and then loaded progressively to $3 \mathrm{MPa}$ again with the same increments, and the test was stopped if the specimen had ruptured.

During each iteration, the increment of wellbore pressure $\Delta P$ was set at $5 \mathrm{MPa}$, and the process of pressurization and depressurization continued until the specimen's final rupture. The designs for the true triaxial volumetric fracturing test with depressurization disturbance are presented in Figure 7. Figure 7(a) is the sketch of the fracturing model, and Figure 7(b) is the design of the loading paths.

\section{Test Results}

4.1. Types of Injection Wells. In this study, the types of injection wells included vertical wells (specimens \#A-1 and \#A-2) and horizontal wells (specimens \#B-1, \#B-2, \#C-1, and \#C-2). Note that the initial stress states of specimens \#A-1, \#A-2, \#B-1, and \#B-2 were uniformly set as $\sigma_{\mathrm{v}}, \sigma_{\mathrm{H}}$, and $\sigma_{\mathrm{h}}$ at 14 , 12 , and $2 \mathrm{MPa}$, respectively. The true triaxial volumetric fracturing tests with three-directional constant loads were carried out on specimens \#A-1, \#B-1, and \#C-1. The tests with one-way pressurization disturbances were performed on specimens \#A-2 and \#B-2, whereas the test with one-way depressurization disturbance was performed on specimen \#C-2.

4.1.1. Variations of Wellbore Pressure. Firstly, the variations of the characteristics of wellbore pressure $P_{\mathrm{w}}$ for specimens $\#$ A-1 and \#B-1 were compared. Figure 8(a) presents the variation curve of fluid pressure in the wellbore versus time for specimen \#A-1 and can be divided into four stages. Additionally, four points, A to D, corresponding to different characteristic pressure values, are denoted. Stage 1 (initial injection of fracturing fluid stage): the fracturing fluid gradually filled the wellbore, and the pressure rose rapidly to Point A (approximately $5 \mathrm{MPa}$ ), then suddenly dropped to $3 \mathrm{MPa}$ and was maintained at this pressure value for $3 \mathrm{~min}$. Point A indicates the crack initiation pressure of the blocking material in the lower part of the wellbore. Stage 2 (crack initiation stage): the wellbore fluid pressure had abruptly dropped twice before it increased rapidly to peak Point $\mathrm{C}$ at $50.3 \mathrm{MPa}$, which is the critical failure strength $P_{\mathrm{f}}$. The first peak point before the first abrupt drop is Point $\mathrm{B}$ at approximately $33 \mathrm{MPa}$, corresponding to the shale rock's crack initiation pressure $P_{\mathrm{i}}$. There are two reasons for this drop. (1) When the fluid pressure is increased to a certain level during the fracturing process, the weak plane of the wellbore wall and natural fractures in the rock will open. (2) The cracks or damaged areas are limited, and thus, the stress will rise rapidly after the sudden drop. Stage 3 (crack growth stage): the fracturing fluid penetrated the cracks, and then the cracks expanded continuously. After Point $\mathrm{C}$, the wellbore fluid pressure began to decrease until it reached $20 \mathrm{MPa}$ at Point $\mathrm{D}$, which is the crack coalescence stress $P_{\mathrm{c}}$. Stage 4 (complete crack penetration): the wellbore fluid pressure was maintained at approximately $20 \mathrm{MPa}$, and the fracturing fluid 
TABLE 1: Experiment program for hydraulic fracturing simulation of shale rock specimens.

\begin{tabular}{lccccc}
\hline $\begin{array}{l}\text { Types of injection } \\
\text { well }\end{array}$ & $\begin{array}{c}\text { Specimen } \\
\text { number }\end{array}$ & $\begin{array}{c}\text { Triaxial stress }(\mathrm{MPa}) \sigma_{\mathrm{v}} \\
/ \sigma_{\mathrm{H}} / \sigma_{\mathrm{h}}\end{array}$ & $\begin{array}{c}\mathrm{SDC} \\
\left(\left(\sigma_{\mathrm{H}}-\sigma_{\mathrm{h}}\right) / \sigma_{\mathrm{h}}\right)\end{array}$ & $\begin{array}{c}\text { Fracturing fluid viscosity } \\
(\mathrm{mPa})\end{array}$ & $\begin{array}{c}\text { Types of stress states } \\
\text { Vertical well }\end{array}$ \\
\#A-1 & $14 / 3 / 2$ & 0.5 & 2.5 & $\begin{array}{c}\text { Constant load } \\
\text { Pressurization disturbance } \\
\text { load }\end{array}$ \\
HA-2 & $14 / 3 / 2$ & 0.5 & 2.5 & $\begin{array}{c}\text { Constant load } \\
\text { Horizontal well }\end{array}$ \\
& \#B-1 & $14 / 3 / 2$ & 0.5 & 2.5 & $\begin{array}{c}\text { Pressurization disturbance } \\
\text { load }\end{array}$ \\
\#-2 & $14 / 3 / 2$ & 0.5 & 2.5 & 2.5 & $\begin{array}{c}\text { Constant load } \\
\text { Depressurization } \\
\text { disturbance load }\end{array}$ \\
\hline
\end{tabular}

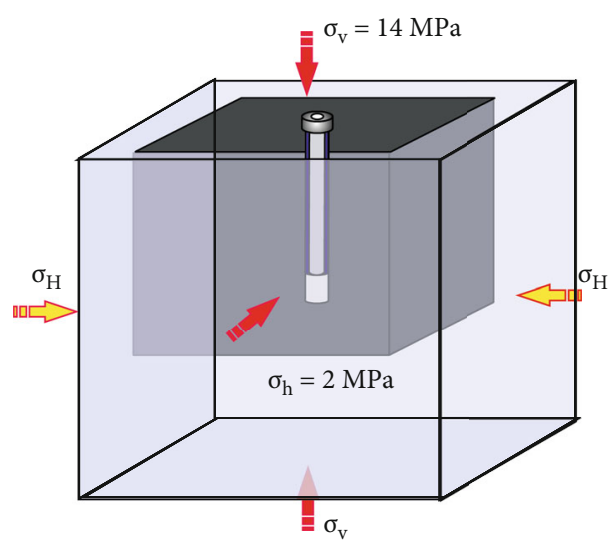

(a) Sketch map of fracing model

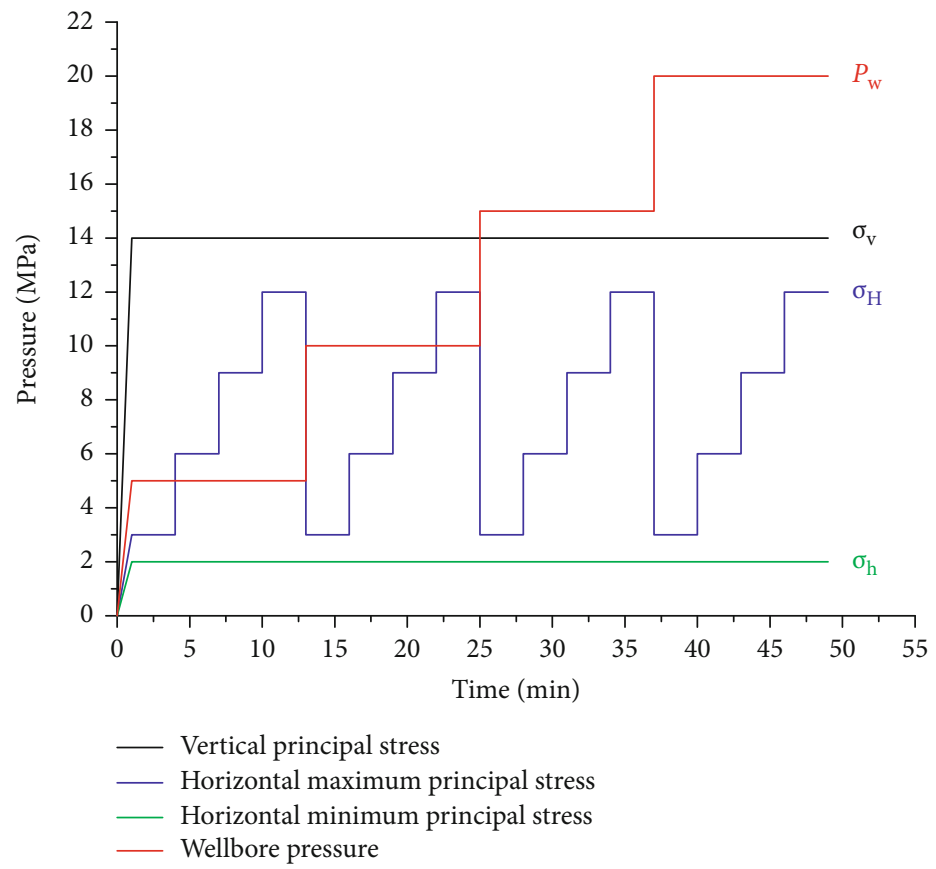

(b) Loading paths

FIGURE 5: Scheme design for volumetric fracing true triaxial test with pressurization disturbance of vertical well (specimen A-2\#).

continuously seeped out of the cracks. After $20 \mathrm{~min}$, the injection of fracturing fluid was stopped, indicating the end of the test.

Figure 8 (b) plots the relationship between the fluid pressure of the wellbore and time for specimen \#B-1. The fracturing process has three obvious stages. Similarly, four characteristic points are indicated on the curve. Stage 1 (initial injection of fracturing fluid stage): the variations in the features are similar to those of specimen \#A-1. Stage 2 (crack initiation stage): the wellbore fluid pressure only experienced one abrupt drop at point $\mathrm{B}$ at $50 \mathrm{MPa}$ corresponding to the crack initiation pressure $P_{\mathrm{i}}$, which indicates the opening of a weak surface or natural crack on the wellbore wall. Then, the pressure rose quickly to the peak value $P_{\mathrm{f}}$ at Point $\mathrm{C}$ at $53 \mathrm{MPa}$. Differing from specimen \#A-1, in Stage 3, the fracturing cracks expanded and penetrated quickly, and then the wellbore fluid pressure rapidly decreased to the $P_{\mathrm{c}}$ value of $15 \mathrm{MPa}$ at Point D. Similarly, the test was ended after approximately $20 \mathrm{~min}$ when the fracturing fluid injection was stopped.

Specimens \#A-1 and \#B-1 have similar critical failure strengths and similar fracturing time of approximately 37 min, whereas they have significantly different crack initiation pressures of $33 \mathrm{MPa}$ and $50 \mathrm{MPa}$, respectively. Notably, compared with specimen \#B-1, the wellbore pressure for specimen \#A-1 displayed more frequent fluctuations before it reached the peak value, indicating more intermittent microcracks or secondary fracture generation. After reaching the peak value, the wellbore pressure gradually decreased for specimen \#A-1, whereas the pressure sharply dropped to the lowest value for specimen \#B-1. This drop was caused by the rapid growth and complete coalescence of cracks, as well as the quick penetration of the fracturing fluid from fracture cracks throughout the entire test piece. 


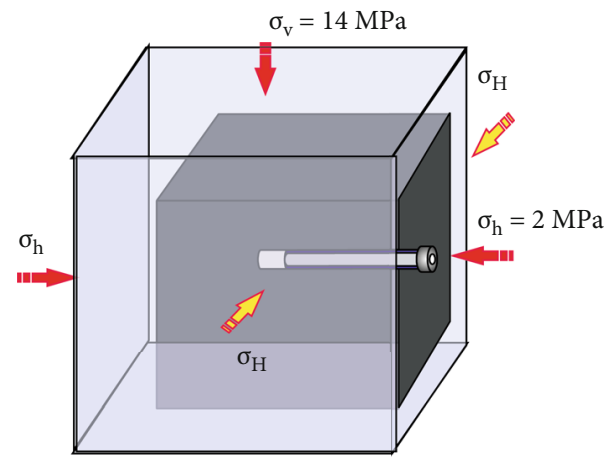

(a) Sketch map of fracing model

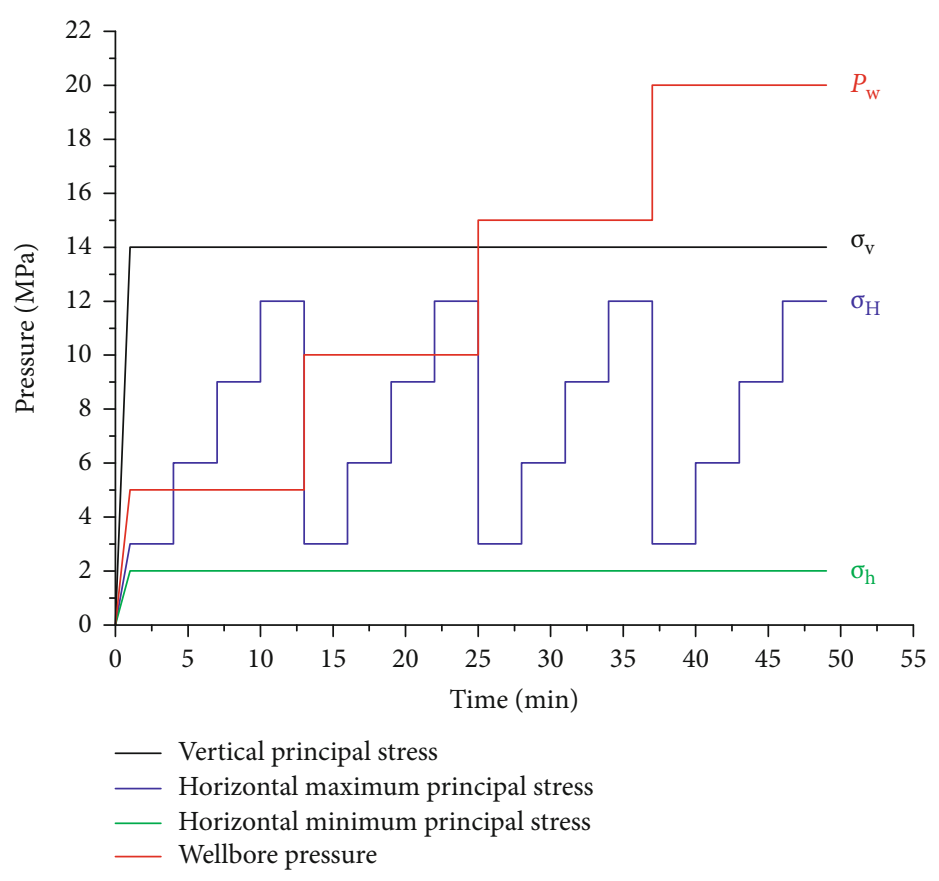

(b) Loading paths

FIGURE 6: Scheme design for true triaxial pressurization disturbance volumetric fracing test of horizontal well (specimen B-2\#).

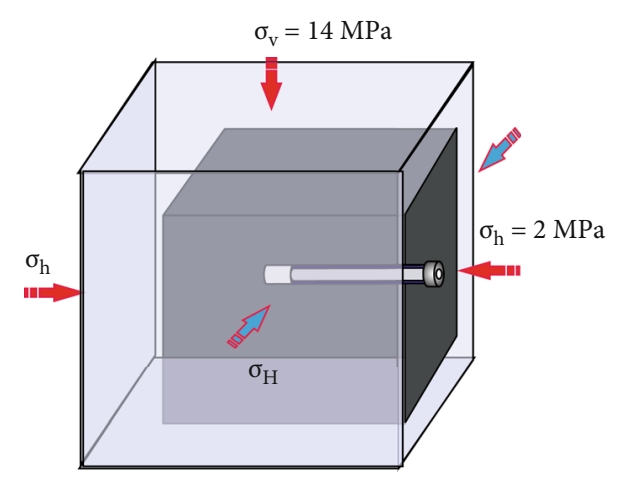

(a) Sketch map of fracing model

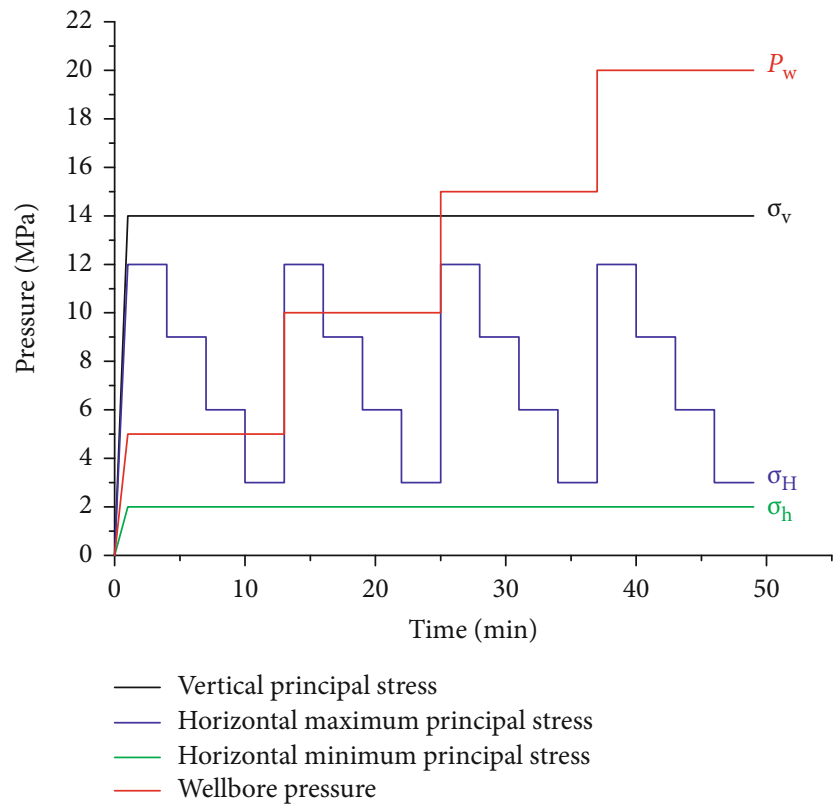

(b) Loading paths

FIGURE 7: Scheme design for true triaxial depressurization disturbance volumetric fracing test of horizontal well (specimen C-2\#).

4.1.2. Fracture Failure Patterns of Shale Rock Specimens. Figure 9 shows the failure patterns of specimen \#A-1. The sketch map of the fracturing model for the vertical well and its corresponding physical model after hydraulic fracturing are presented in Figures 9(a) and 9(b), respectively. The fracture cracks and their expansion directions are denoted using white chalk. After removing the outer wrapped concrete, the fracture network of shale rock can be observed from the top view (see Figure 9(c)). The main crack that runs through the entire specimen extends along the maximum horizontal principal stress direction, therefore, leading to the primary rupture surface formation. Moreover, the fracture process is accompanied by an oblique secondary crack development, which runs through the rock's center upward to the right, 


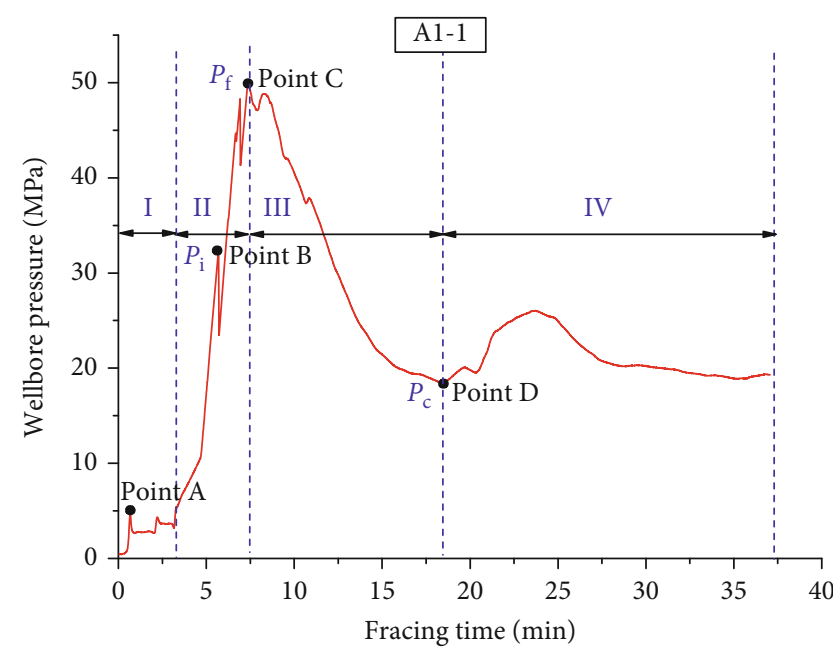

(a) Specimen \#A-1

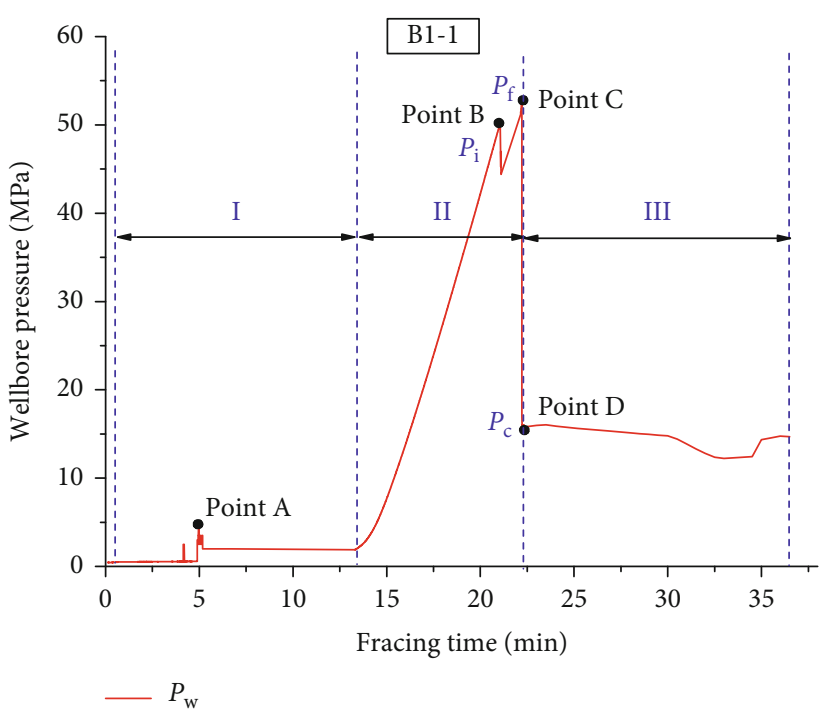

(b) Specimen \#B-1

Figure 8: Fluid pressure in wellbore versus fracing time for specimens \#A-1 and \#B-1.

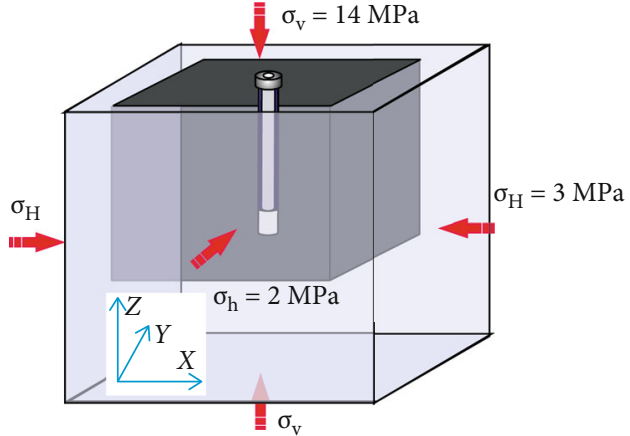

(a) Sketch map of fracing model

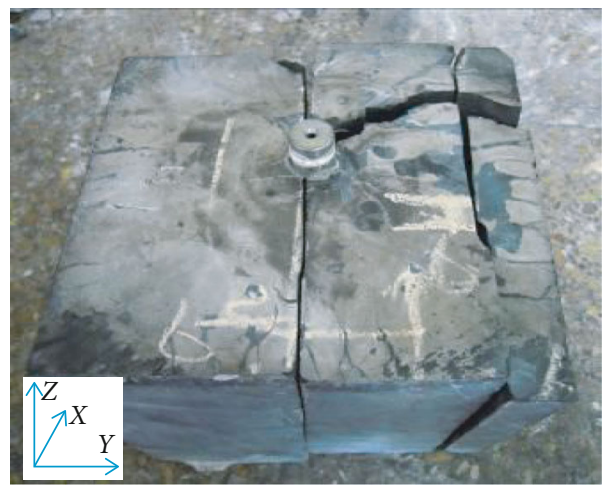

(c) Top view of shale fracture networks

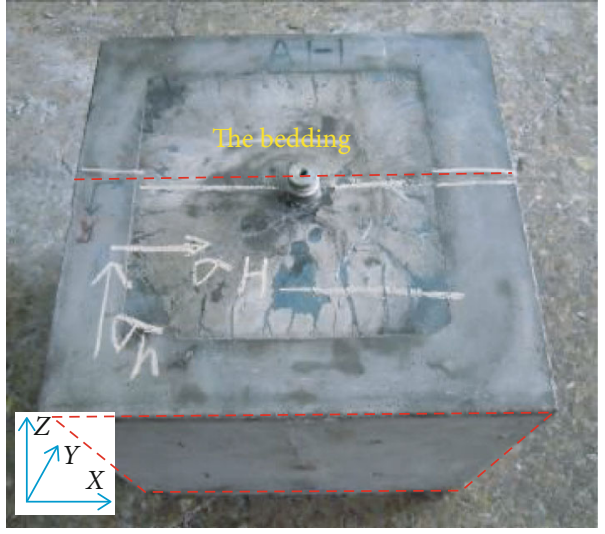

(b) Fracing model after hydraulic fracture

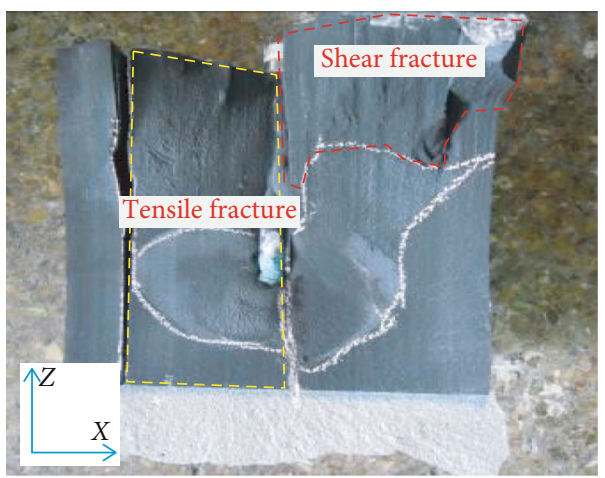

(d) Main rupture surface

Figure 9: Failure patterns of specimen \#A-1.

causing the formation of a secondary rupture surface. Another crack parallel to the maximum horizontal principal stress direction propagates along the right edge for approximately two-thirds of the side length of the shale rock.
Figure 9(d) shows the main rupture surface of shale rock. The distribution area of fracturing fluid with the tracer, which is enclosed by white chalk, can be clearly observed. The yellow dotted box represents the tensile fracture surface, 


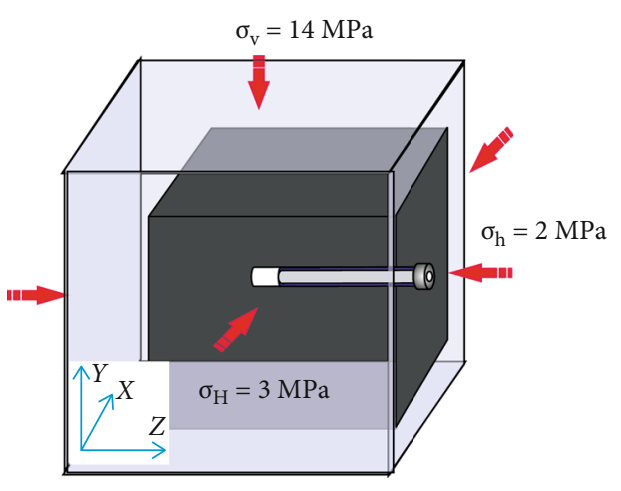

(a) Sketch map of fracing model

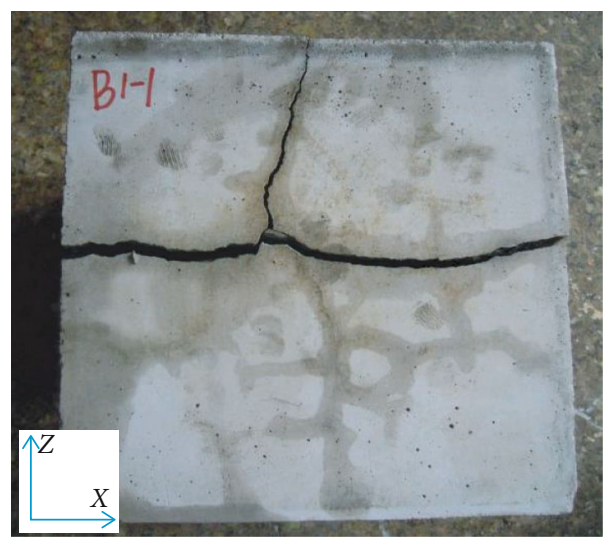

(c) Side view of shale fracture networks

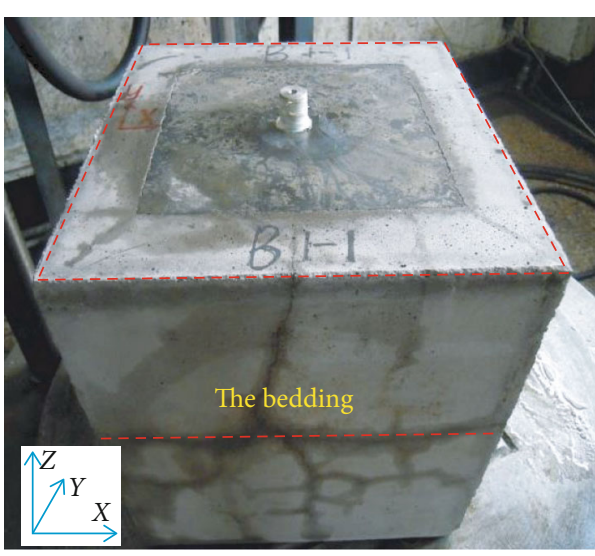

(b) Fracing model after hydraulic fracture

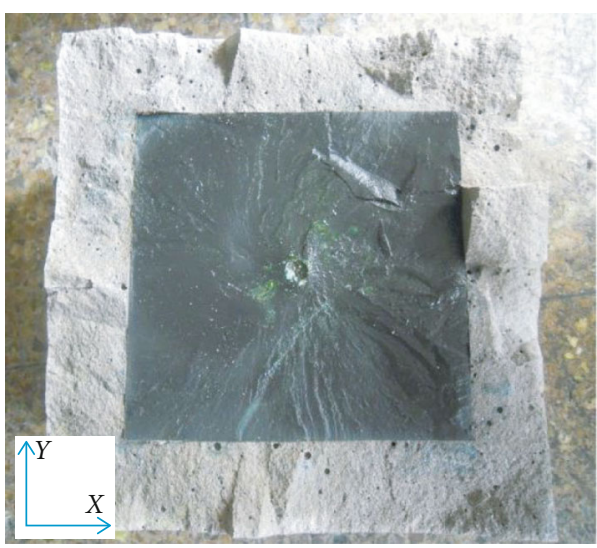

(d) Main rupture surface

Figure 10: Failure patterns of specimen \#B-1.

and it extends along the direction of the shale bedding. The main rupture surface determined by the $X$ - and $Z$-directions had formed due to tensile stress. Furthermore, the red dotted box represents the shear fracture surface. There is an angle of $45^{\circ}$ between the fracture surface and the maximum principal stress surface of $x-z$, with traces of sliding on the fracture surface. Therefore, the edge of the shale specimen primarily experienced shear fracturing.

Figure 10 shows the failure patterns of specimen \#B-1. The sketch map of the fracturing model for the horizontal well and its corresponding physical model after hydraulic fracturing are presented in Figures 10(a) and 10(b), respectively. The fracture network of shale rock can be observed from the side view (see Figure 10(c)), and the fracture cracks and their expansion directions are denoted. A major crack runs through the shale rock from the left to the right along the maximum horizontal principal stress direction, therefore, leading to the main rupture surface formation. Meanwhile, a secondary crack extends approximately parallel to the wellbore direction and intersects the testing specimen surface at its center edge position. After opening the outer wrapped concrete, the main rupture surface of the shale rock was exposed to the air (see Figure 10(d)). The green tracer was distributed mainly along the vertical principal stress direction ( $Y$-direction), indicating that the crack had first run along the $Y$-direction and then expanded toward the $X$ -direction branch, eventually resulting in the formation of the primary rupture surface perpendicular to the wellbore.

In the specimen \#A-1 (vertical well), the bedding direction of shale rock is parallel to the well's direction, which is along the direction of the maximum horizontal principal stress. For the specimen \#B-1 (horizontal well), the bedding direction of shale rock is perpendicular to the well's direction, which is also along the direction of the maximum horizontal principal stress. The red dotted line shows these specimens in Figures 7 and 8. Comparing the failure patterns of specimens \#A-1 and \#B-1, they both have main rupture surfaces that are determined by the maximum principal stress and intersected with secondary cracks. After being fractured, specimen \#A-1 not only has one main rupture surface in the bedding direction but also has two secondary rupture surfaces: one is obliquely intersecting the main rupture surface and the other, located along the specimen's edge, is parallel to the main rupture surface. Because of the deflection of the hydraulic fracture of specimen \#A-1 during expansion, there are both tensile fracture planes along the bedding direction and shear fracture planes oblique to the bedding on the main fracture plane. However, the main fracture surface of specimen \#B-1 had only propagated along the bedding in the maximum principal stress plane, and the fracture does not deflect. Therefore, the roughness of the rupture surfaces of specimen \#A-1 is much higher than that of specimen \#B-1. Moreover, 

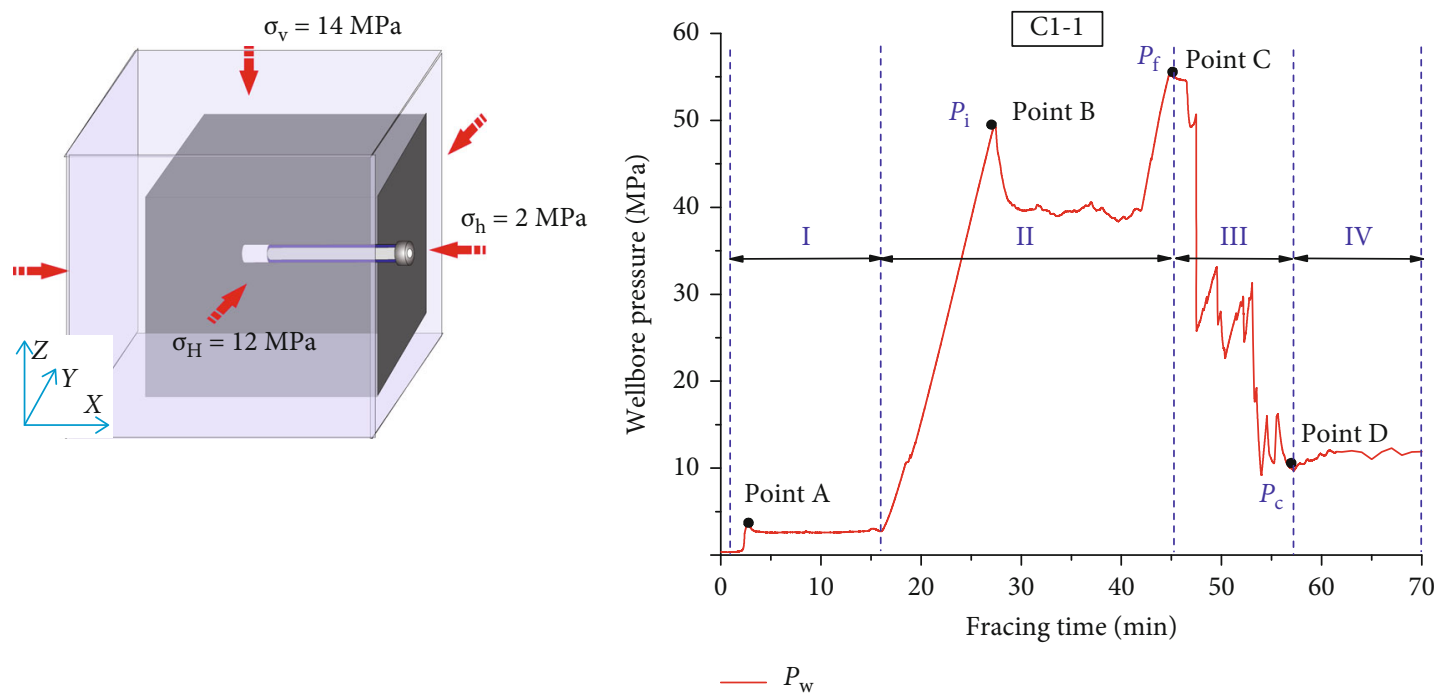

(a) Sketch map of fracing model

(b) Curve of wellbore pressure versus fracing time

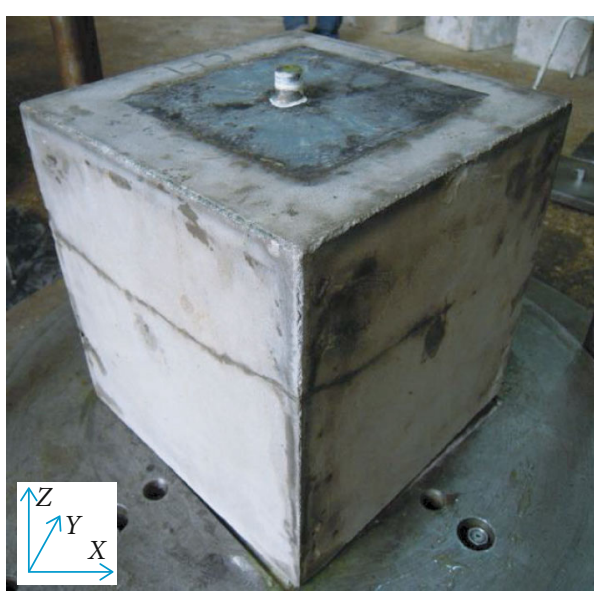

(c) Fracing model after hydraulic fracture

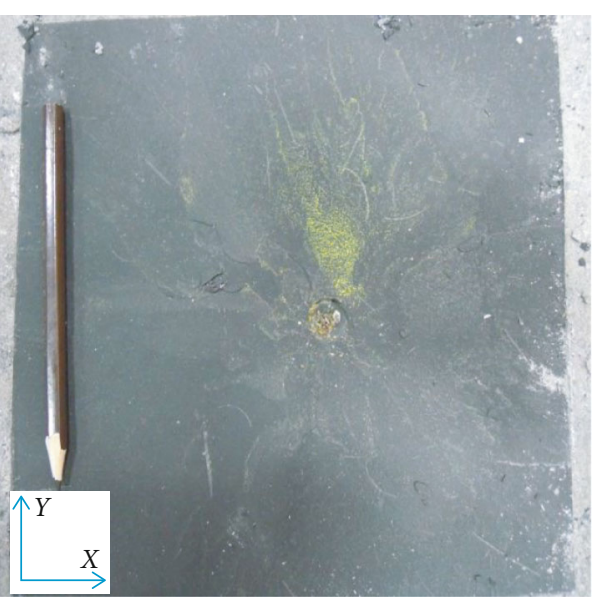

(d) Main rupture surface

FIGURE 11: Results of volumetric fracing test for specimen \#C-1.

due to the influence of the bedding surface, specimen \#B-1 has the primary rupture surface perpendicular to the wellbore direction and only has a single secondary crack that crosses the main rupture surface at approximately a right angle. According to the above comparative analysis, the shale rock failure patterns under volumetric fracturing and their crack network complexities are closely related to the relationship between the bedding direction and the well direction.

\subsection{Influence of In Situ Stress Difference Coefficient. Similar to} specimen \#B-1, the fracturing simulation test for the horizontal well under a constant load was also conducted on specimen \#C-1. The only difference is that the three initial principal stresses were set as $\sigma_{\mathrm{v}}, \sigma_{\mathrm{H}}$, and $\sigma_{\mathrm{h}}$ at 14,3 , and $2 \mathrm{MPa}$, respectively, for specimen $\# \mathrm{~B}-1$, whereas they were $\sigma_{\mathrm{v}}, \sigma_{\mathrm{H}}$, and $\sigma_{\mathrm{h}}$ at 14,12 , and $2 \mathrm{MPa}$, respectively, for specimen \#C-1. The following formula defines the in situ stress difference coefficient:

$$
K=\frac{\sigma_{H}-\sigma_{h}}{\sigma_{h}}
$$

where $K$ is the in situ stress difference coefficient, $\sigma_{\mathrm{H}}$ is the maximum horizontal in situ stress, and $\sigma_{\mathrm{h}}$ is the minimum horizontal in situ stress. The in situ stress difference coefficients of Equation (1) are 0.5 and 5 for specimens \#B-1 and \#C-1, respectively. The sketch map of the fracturing model for specimen \#C-1 is presented in Figure 11(a), and Figure 11(b) illustrates the variations in the fluid pressure of wellbore versus time. Unlike specimen $\# \mathrm{~B}-1$, the curve of fluid pressure, where four characteristic points are denoted, can be divided into four stages. (1) The first stage is the initial injection of fracturing fluid, and the peak value Point A on the curve corresponds to the crack initiation pressure of the blocking material in the bottom of the wellbore. (2) The second stage is the crack initiation stage, where there are two peak value points. The first peak Point $\mathrm{B}$ is located at 49.5 MPa, whereas the second peak Point $\mathrm{C}$ at 55.2 MPa indicates the critical failure strength $P_{\mathrm{f}}$ for the specimen. Point $\mathrm{B}$ corresponds to the crack initiation pressure $P_{\mathrm{i}}$ of the wellbore wall. After that, the crack continuously propagated forward as the fracturing fluid was pumped into the wellbore, and then the crack stopped growing without running throughout 


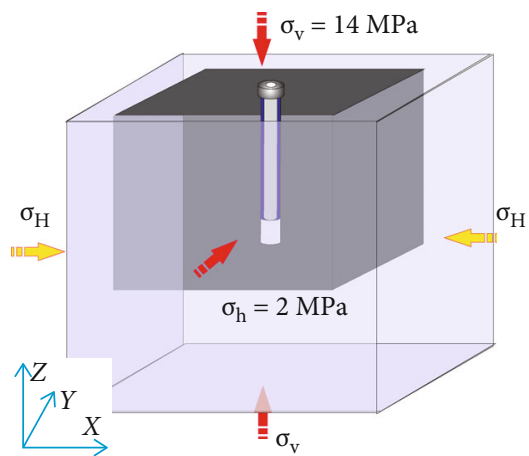

(a) Sketch map of fracing model

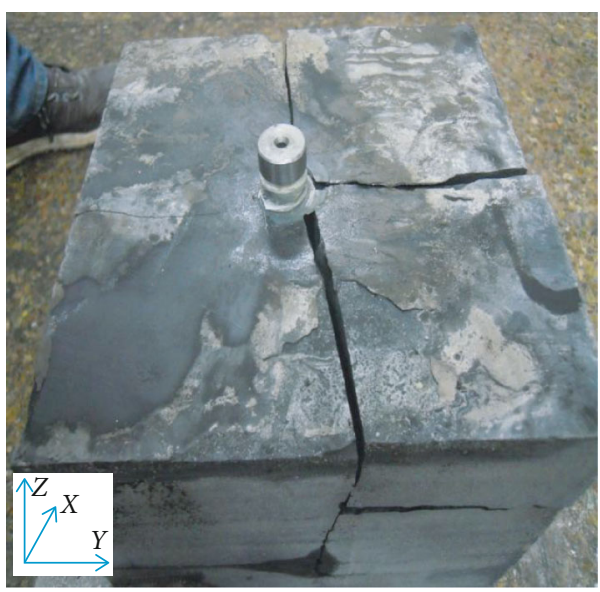

(c) Fracing model after hydraulic fracture

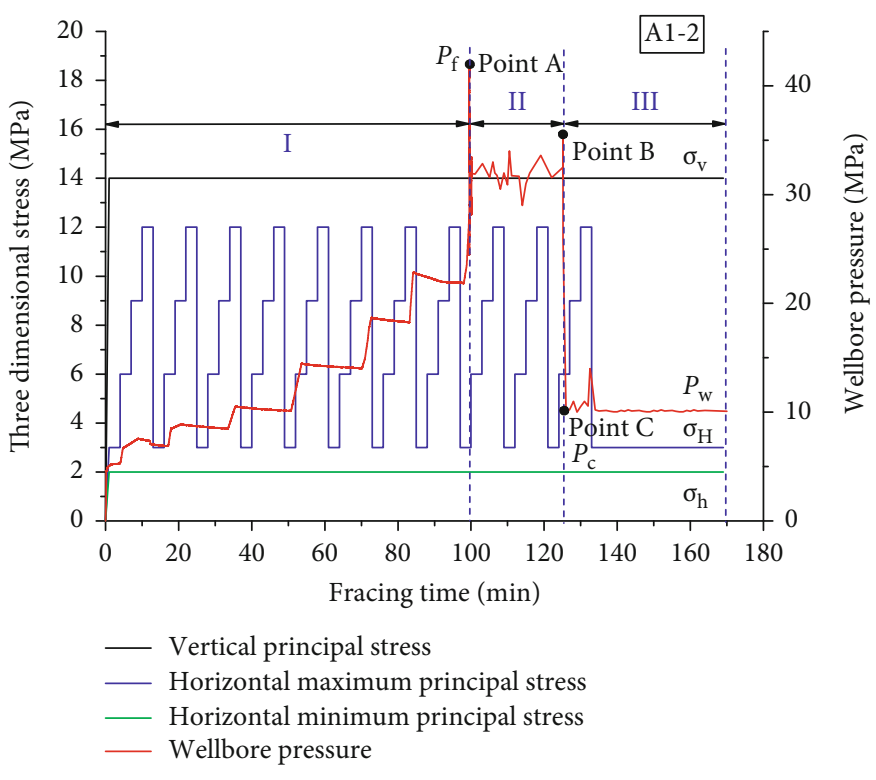

(b) Loading-unloading paths and wellbore pressure versus fracing time

FIGURE 12: Loading-unloading paths and failure patterns for specimen \#A-2.

the specimen. At this time, the fluid pressure rose quickly to Point $\mathrm{C}$, reaching the critical failure strength, which can be interpreted by the opening of the weak planes or natural cracks. However, the fractured or damaged area is severely limited, therefore leading to the rapid rise of pressure after the stress drop. (3) The third stage is the crack expansion and then coalescence stage during which the wellbore pressure fluctuated substantially and dropped quickly to $10 \mathrm{MPa}$ at Point $\mathrm{D}$ (indicating the value of $P_{\mathrm{c}}$ ). It can be observed at this stage that the fracturing fluid gradually penetrated the fracture's cracks, causing their continuous expansion. (4) During the fourth stage, the cracks had completely penetrated, and the fluid pressure was maintained at approximately $10 \mathrm{MPa}$.

Figure 11(c) shows the failure patterns of specimen \#C-1, without any cracks on the upper surface of the specimen. There is only a visible horizontal primary crack (in the $X-Y$ plane) from the lateral side of the specimen, where the fracturing fluid had continually seeped out. Figure 11(d) shows

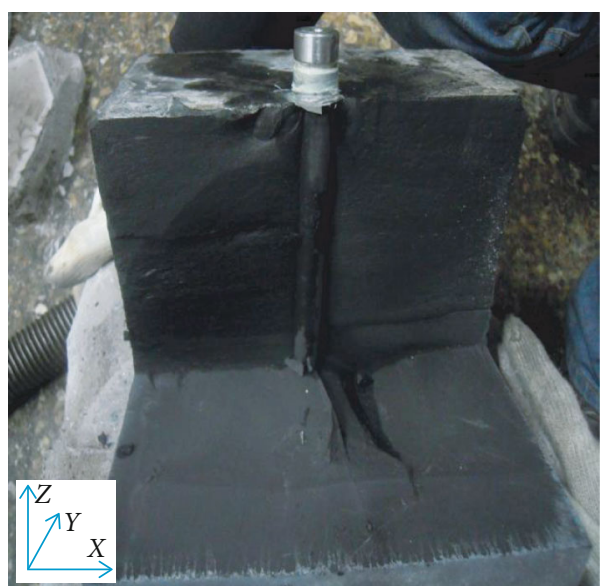

(d) Main rupture surface

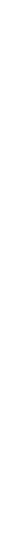




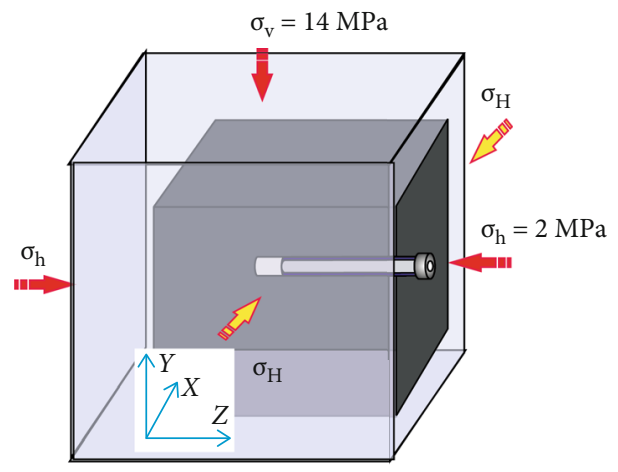

(a) Sketch map of fracing model

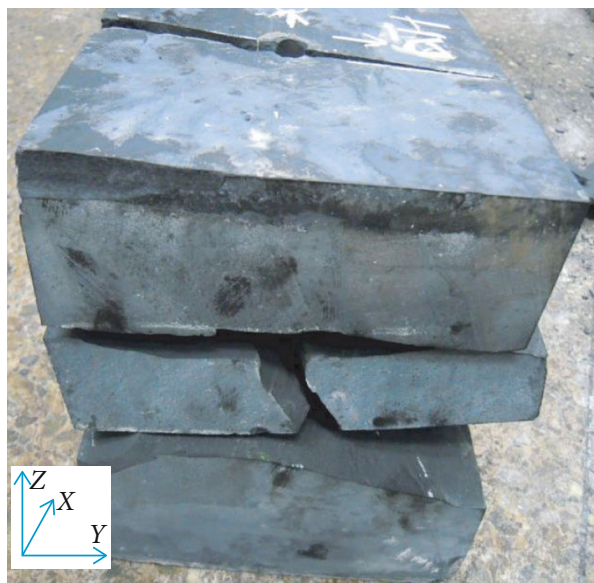

(c) Fracing model after hydraulic fracture

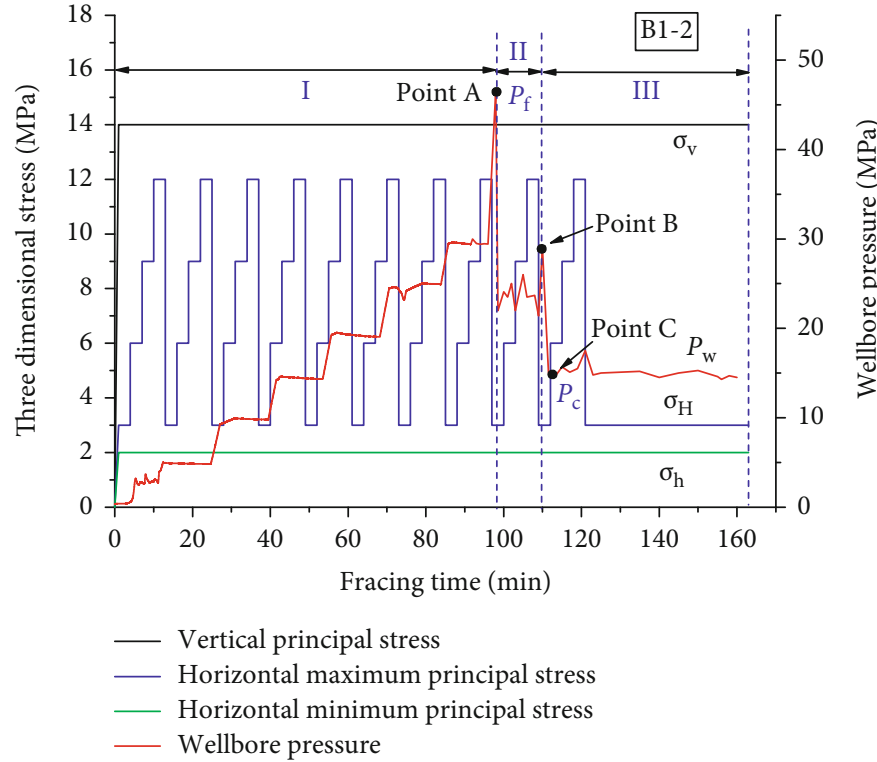

(b) Loading-unloading paths and wellbore pressure versus fracing time

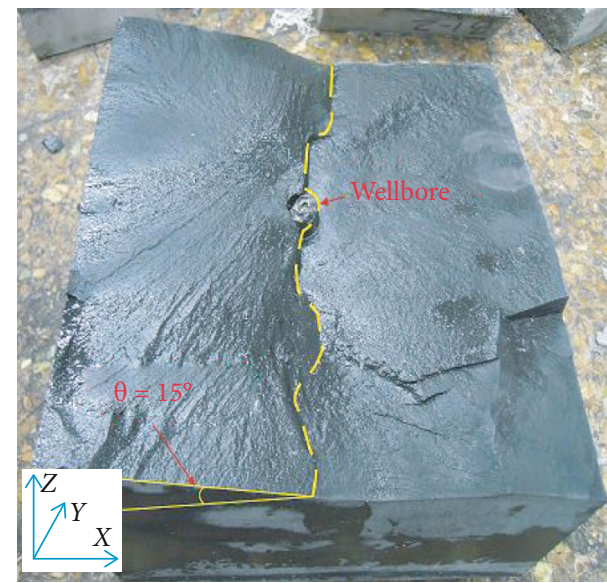

(d) Main rupture surface

FIGURE 13: Loading-unloading paths and failure patterns for specimen \#B-2.

simulate fracturing failure of shale rock or other similar material under disturbance loads were used to reveal the influencing mechanisms of external disturbance on hydraulic fracturing.

4.3.1. Fracturing Test for Vertical Well under One-Way Pressurization Disturbance. Specimen \#A-2 was used to simulate the hydraulic fracturing process with a one-way step pressurization disturbance in the maximum horizontal principal stress direction. The sketch map of the fracturing model for specimen \#C-1 is presented in Figure 12(a), and the variations in the fluid pressure of the wellbore versus time are plotted in Figure 12(b). As shown in Figure 12(b), the red curve, which indicates the wellbore fluid pressure $P_{\mathrm{w}}$, can be divided into three stages. (1) The first stage lasts approximately $100 \mathrm{~min}$, where $P_{\mathrm{w}}$ is increased in increments of $3 \mathrm{MPa}$ for each cycle of loading and unloading of the maximum horizontal principal stress and remains unchanged for approximately $3 \mathrm{~min}$. (2) The wellbore failure and crack propagation occur during the second stage. $P_{\mathrm{w}}$ arrives at the peak Point A (corresponding to critical failure strength) at approximately $42.3 \mathrm{MPa}$ and then drops rapidly to $31 \mathrm{MPa}$, and then fluctuates slightly around $31 \mathrm{MPa}$ until it reaches the second peak Point $\mathrm{B}$ at approximately $35 \mathrm{MPa}$. The entire second stage lasted approximately $25 \mathrm{~min}$. (3) Entering into the third stage, the crack penetrates the specimen, and $P_{\mathrm{w}}$ abruptly falls to the Point $\mathrm{C}$ at $10 \mathrm{MPa}$ (indicating the value of $P_{c}$ ) and then remains unchanged, with the continuous flow of the fracturing fluid out of the cracks. It was determined that $10 \mathrm{MPa}$ is the necessary pressure to maintain open hydraulic fractures under the threedimensional stress states of $\sigma_{\mathrm{v}}, \sigma_{\mathrm{H}}$, and $\sigma_{\mathrm{h}}$ at 14,3 , and $2 \mathrm{MPa}$, respectively.

Figure 12 illustrates that before $P_{\mathrm{w}}$ reaches peak Point A, the maximum horizontal principal stress $\sigma_{\mathrm{H}}$ experiences eight cycles of loading and unloading processes, whereas in 


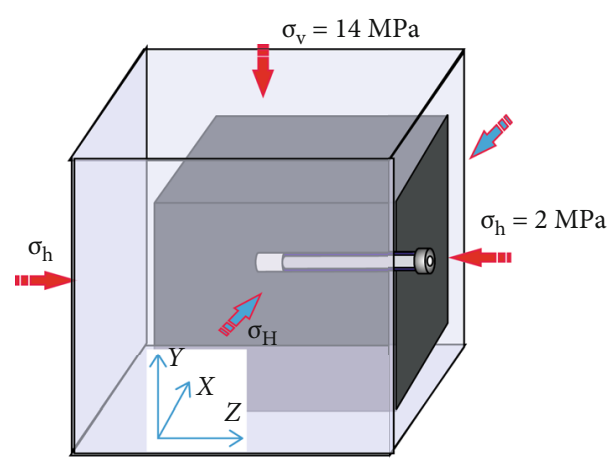

(a) Sketch map of fracing model

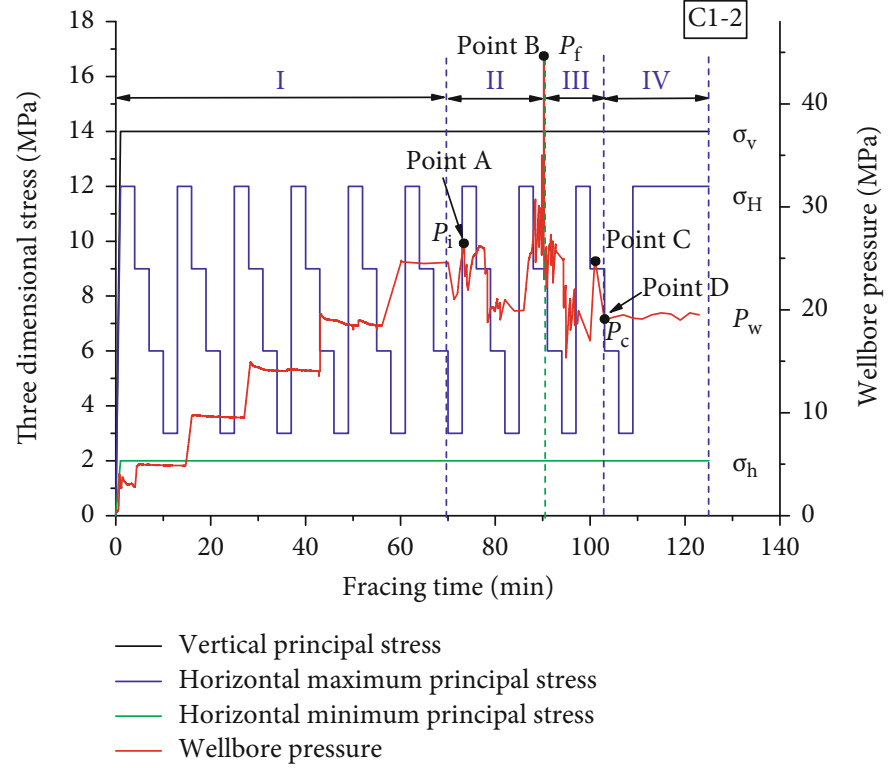

(b) Loading-unloading paths and wellbore pressure versus fracing time

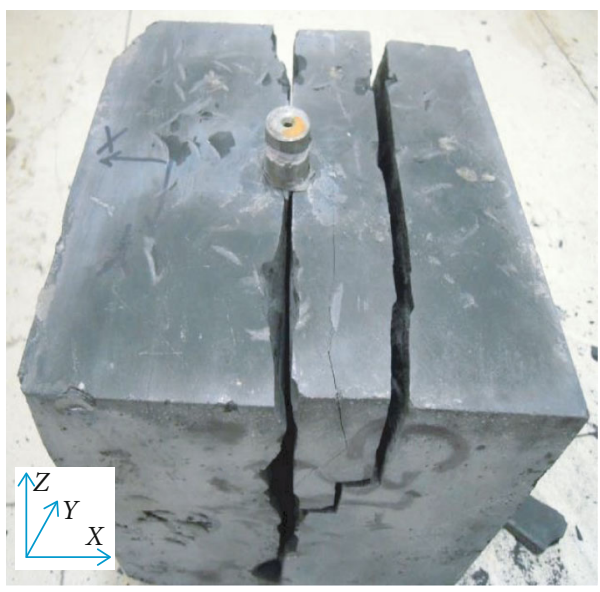

(c) Fracing model after hydraulic fracture

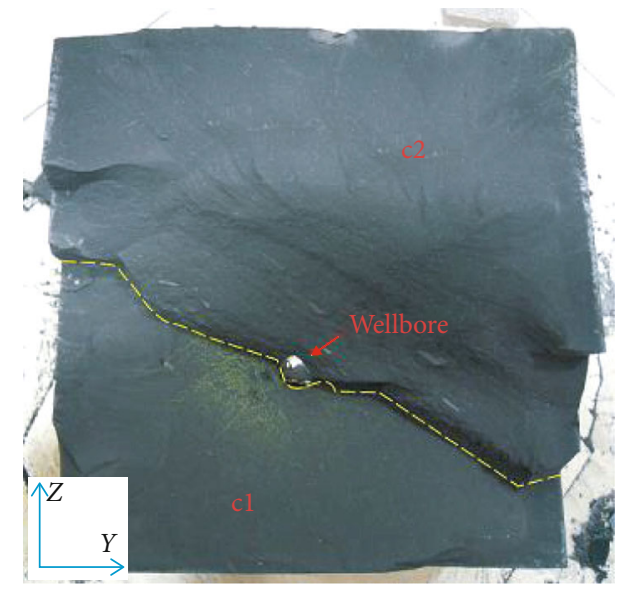

(d) Main rupture surface

FIGURE 14: Loading-unloading paths and failure patterns for specimen \#C-2.

each cycle of disturbance, $P_{\mathrm{w}}$ always has a slight decrease. In the $9^{\text {th }}$ cycle, with $\sigma_{\mathrm{H}}$ being kept constant at $3 \mathrm{MPa}, P_{\mathrm{w}}$ increases quickly to Point $\mathrm{A}$ and then decreases sharply, which can help us distinctly determine the crack initiation of the shale rock in the wellbore. Figure 12(c) presents the crack distribution of the rock specimen. Except for the $Z$ -direction primary fracture surface, there are also secondary fracture surfaces that developed along the $X$ - and $Y$-directions and had not penetrated the entire specimen. Figure 12(d) shows the main vertical rupture surface that was distributed symmetrically along the wellbore direction and the secondary horizontal rupture surface that was formed at the bottom of the wellbore.

4.3.2. Fracturing Test for Horizontal Well under One-Way Pressurization Disturbance. Specimen \#B-2 was used to simulate the hydraulic fracturing process for a horizontal well under a one-way step pressurization disturbance along the maximum horizontal principal stress direction. Figure 13(a) shows the sketch map of the corresponding fracturing model, and Figure 13(b) describes the relationship between the three-dimensional stresses and wellbore pressure versus time. As Figure 13(b) shows, the maximum horizontal principal stress $\sigma_{\mathrm{H}}$ experiences eight cycles of loading and unloading processes before the wellbore fluid pressure $P_{\mathrm{w}}$ arrives at the critical failure strength of the shale specimen. Unlike specimen \#A-2, the critical failure strength $P_{\mathrm{f}}$ is 46.6 MPa at Point A, whereas the necessary pressure to maintain the open hydraulic fractures after crack coalescence is $15 \mathrm{MPa}$ at Point $\mathrm{C}$ (indicating the value of $P_{\mathrm{c}}$ ). During each cycle of disturbance, though no fracturing fluid had been injected into the wellbore, $P_{\mathrm{w}}$ slightly decreased in each step, which may be caused by the wellbore leakage.

The fracturing specimens for the horizontal and vertical wells displayed significant differences in the failure patterns, and the failure modes for specimen \#B-2 are presented in 
Figures 13(c) and 13(d). Figure 13(c) presents the fracture network from the side view, and it can be seen that the shale rock was fractured into several pieces. There are two penetrating rupture surfaces that are approximately perpendicular to the wellbore direction and two nonpenetrating rupture surfaces that are along the wellbore direction. As shown in Figure 11(d), the direction along the wellbore has been set as the $z$-axis of the three-dimensional coordinate system. The right side of the dotted line is an approximately horizontal rupture plane determined by the $X$ - and $Y$ -directions, whereas the left side of the dotted line is an inclined rupture plane with a dip angle of $15^{\circ}$, and thus, the shear slip failure of the rock can be clearly observed. Except for the main rupture surface, there are also secondary rupture surfaces along or vertical to the wellbore direction without penetrating the entire specimen. The main rupture surface had been formed at the wellbore bottom, where the primary crack extends longitudinally, as indicated with the yellow dotted line.

4.3.3. Fracturing Test for Horizontal Well under One-Way Depressurization Disturbance. Specimen \#C-2 was used to simulate the hydraulic fracturing process for a horizontal well under a one-way step depressurization disturbance along the maximum horizontal principal stress direction, and its corresponding sketch map of the fracturing model is shown in Figure 14(a). Figure 14(b) plots the curves of the three-dimensional stresses and wellbore pressure versus time. The red curve, which indicates the wellbore fluid pressure of $P_{\mathrm{w}}$, can be divided into four stages. (1) The first stage is the stepped growth stage, and $P_{\mathrm{w}}$ was changed at increments of $3 \mathrm{MPa}$ in each lateral depressurization disturbance and finally reaches Point A at approximately $26 \mathrm{MPa}$ (corresponding to crack initiation stress $P_{\mathrm{i}}$ ). The duration of this stage is approximately $100 \mathrm{~min}$. (2) The second stage, where $P_{\mathrm{w}}$ displays significant fluctuations and finally arrives at the peak point $\mathrm{B}$ (corresponding to critical failure strength $P_{\mathrm{f}}$ ) at approximately $44.3 \mathrm{MPa}$, is the microcrack expansion process. (3) Entering into the third stage, the microcracks experience further propagation and then form into macrocracks, where $P_{\mathrm{w}}$ drops rapidly to approximately $15 \mathrm{MPa}$ and then fluctuates to the second peak point $C$ at approximately $25 \mathrm{MPa}$. The entire third stage lasts approximately $10 \mathrm{~min}$. (4) During the last stage, the macrocracks had begun to penetrate the rock, and $P_{\mathrm{w}}$ abruptly falls to Point D at $20 \mathrm{MPa}$ (corresponding to crack coalescence stress $P_{\mathrm{c}}$ ). Then, $P_{\mathrm{w}}$ remains unchanged, whereas the three-dimensional principal stresses were restored to their initial values and also remained unchanged until the end of the test.

The failure pattern of specimen \#C-2 under the one-way step depressurization disturbance is much different from that of specimen \#B-2 under the one-way step pressurization disturbance, which are presented in Figures 14(c) and 14(d). Figure 14(c) shows the fracture network of the shale rock from the side view. A vertical main crack cl runs through the entire specimen, leading to the primary rupture surface formation. Meanwhile, a secondary crack c2 extends up obliquely from the center position of the main crack until it intersects the test specimen's upper surface edge, eventually resulting in the formation of the secondary rupture surface parallel to the main rupture surface. Moreover, the secondary crack c2 has an irregular shape with a slightly serrated border.

From Figure 14(d), the fracturing fluid seepage can be clearly observed on the main rupture surface determined by the $Y-Z$ axis of shale rock. The main rupture surface had formed and developed at the bottom of the wellbore and then extended up obliquely along the secondary crack c2, starting from the yellow dotted line.

\section{Conclusions}

In this study, volumetric fracturing tests under different stress states were conducted on shale using the true triaxial testing system. The influences of injection well types and in situ stress difference coefficients, as well as disturbance loads, on the failure properties and crack propagation rules of shale were investigated. The test results show the following. (1) Under the constant three-directional loads, the critical failure strengths for shale rock specimens \#A-1, \#B-1, and \#C-1 were 50.3 MPa, 53 MPa, and 55.2 $\mathrm{MPa}$, respectively, and displayed an increasing trend with the increase in horizontal pressure on the wellbore. (2) Specimens \#A-1 and \#B-1 were under the same three-dimensional stress states. For both the vertical well and the horizontal well, the main rupture surface was parallel to the maximum principal stress surface, and the shale failure patterns from volumetric fracturing and their crack network complexities were found to be closely related to the relationship between the bedding direction and the well direction. (3) Comparing shale rock specimens \#B-1 and $\# \mathrm{C}-1$, the in situ stress difference coefficients were 0.5 and 5 for specimen \#B-1 and \#C-1, respectively. The results show that \#B-1 $(K=0.5)$ more readily formed complex fracturing cracks, and \#C-1 $(K=5)$ displayed a slightly larger failure strength than \#B-1. (4) The critical failure strengths for specimens \#A-2, \#B-2, and \#C-2 with the disturbance load were $42.3 \mathrm{MPa}, 46.6 \mathrm{MPa}$, and $44.3 \mathrm{MPa}$, respectively. The critical failure strength of each specimen was approximately $10 \mathrm{MPa}$ lower than with the constant load, which indicates that the rock specimen subjected to a disturbance load under the true triaxial state is much more easily fractured. (5) For the rock specimen under the disturbance load, the necessary pressure to maintain the open hydraulic fractures after crack coalescence is closely related to the true triaxial threedimensional stresses. For example, specimen \#C-2 had the largest pressure of $20 \mathrm{MPa}$, whereas specimen \#A-2 had the smallest pressure of $10 \mathrm{MPa}$. (6) In the fracturing process of the horizontal well, the specimen under the one-way depressurization disturbance was more likely to develop crack propagation. All of these research findings could provide a theoretical basis and technical support for the engineering practices, such as multistage fracturing or multiwell synchronous fracturing operations in the exploitation of shale gas.

\section{Data Availability}

The [DATA TYPE] data used to support the findings of this study are included within the article. 


\section{Conflicts of Interest}

The authors declare that they have no conflicts of interest.

\section{Acknowledgments}

This work was financially supported by the National Natural Science Foundation of China (41807254, 51704120, and 41741019), the China Postdoctoral Science Foundation (2020M682372), the Young Talent Support Project of Henan Province (2021HYTP013), the National Key Research and Development Project (2019YFC1509704), and the Key Projects of the NSFC-Henan Joint Fund (U1704243).

\section{References}

[1] J. D. Arthur, B. Langhus, and D. Alleman, "An overview of modern shale gas development in the United States," All Consulting, vol. 3, pp. 14-17, 2008.

[2] X. Zhang, Y. Lu, J. Tang, Z. Zhou, and Y. Liao, "Experimental study on fracture initiation and propagation in shale using supercritical carbon dioxide fracturing," Fuel, vol. 190, pp. 370-378, 2017.

[3] C. R. Clarkson, N. Solano, R. M. Bustin et al., "Pore structure characterization of north American shale gas reservoirs using USANS/SANS, gas adsorption, and mercury intrusion," Fuel, vol. 103, pp. 606-616, 2013.

[4] M. J. Economides, R. E. Oligney, and P. E. Lewis, "U.S. natural gas in 2011 and beyond," Journal of Natural Gas Science and Engineering, vol. 8, pp. 2-8, 2012.

[5] M. J. Mayerhofer, E. P. Lolon, J. E. Youngblood, and J. R. Heinze, "Integration of microseismic fracture mapping results with numerical fracture network production modeling in the Barnett shale," in Paper SPE 102103 presented at the SPE Annual Technical Conference and Exhibition, pp. 24-27, San Antonio, Texas, 2006.

[6] C. Shi, S. N. Wang, L. Liu, Q. Meng, and Q. Zhang, "Mesomechanical simulation of direct shear test on outwash deposits with granular discrete element method," Journal of Central South University, vol. 20, no. 4, pp. 1094-1102, 2013.

[7] Z. Tao, C. Zhu, M. He, and M. Karakus, "A physical modelingbased study on the control mechanisms of negative Poisson's ratio anchor cable on the stratified toppling deformation of anti-inclined slopes," International Journal of Rock Mechanics and Mining Sciences, vol. 138, p. 104632, 2021.

[8] Y. Wang, B. Zhang, S. H. Gao, and C. H. Li, "Investigation on the effect of freeze-thaw on fracture mode classification in marble subjected to multi-level cyclic loads," Theoretical and Applied Fracture Mechanics, vol. 111, p. 102847, 2021.

[9] D. Yin, S. Chen, Y. Ge, and R. Liu, "Mechanical properties of rock-coal bi-material samples with different lithologies under uniaxial loading," Journal of Materials Research and Technology, vol. 10, pp. 322-338, 2021.

[10] Q. Meng, H. Wang, M. Cai, W. Xu, X. Zhuang, and T. Rabczuk, "Three-dimensional mesoscale computational modeling of soil-rock mixtures with concave particles," Engineering Geology, vol. 277, p. 105802, 2020.

[11] Z. Li, G. S. Liu, W. T. Ren, J. J. Fang, Q. H. Zhu, and Z. L. Dun, "Multiscale laboratory study and numerical analysis of waterweakening effect on shale," Advances in Materials Science and Engineering, vol. 2020, Article ID 5263431, 14 pages, 2020.
[12] C. Wang, J. Zhang, Y. Zang et al., “Time-dependent coal permeability: impact of gas transport from coal cleats to matrices," Journal of Natural Gas Science and Engineering, vol. 88, p. 103806, 2021.

[13] M. K. Fisher, B. M. Davidson, A. K. Goodwin, E. O. Fielder, W. S. Buckler, and N. P. Steinsberger, "Integrating fracture mapping technologies to optimize stimulations in the Barnett shale," in Paper SPE 77411 presented at the SPE Annual Technical Conference and Exhibition, San Antonio, Texas, 2002.

[14] M. K. Fisher, J. R. Heinze, C. D. Harris, B. M. Davidson, C. A. Wright, and K. P. Dunn, "Optimizing horizontal completion techniques in the Barnett shale using microseismic fracture mapping," in Paper SPE 90051 presented at the SPE Annual Technical Conference and Exhibition, pp. 26-29, Houston, Texas, 2004.

[15] S. C. Maxwell, T. I. Urbancik, N. P. Steinsberger, and R. Zinno, "Microseismic imaging of hydraulic fracture complexity in the Barnett shale," in Paper SPE 77440 presented at the SPE Annual Technical Conference and Exhibition, San Antonio, Texas, 2002.

[16] M. J. J. Mayerhofer, E. P. P. Lolon, N. R. R. Warpinski, C. L. L. Cipolla, D. Walser, and C. M. M. Rightmire, "What is stimulated reservoir volume?," SPE Production \& Operations, vol. 25, no. 1, pp. 89-98, 2010.

[17] C. L. Cipolla, N. R. Warpinski, M. J. Mayerhofer, E. P. Lolon, and M. C. Vincent, "The relationship between fracture complexity, reservoir properties, and fracture treatment design," in In: SPE 115769, presented at the SPE Annual Technical Conference and Exhibition, pp. 21-24, Denver, Colorado, 2010.

[18] N. R. Warpinski, M. J. Mayerhofer, and M. C. Vincent, "Stimulating unconventional reservoirs: maximizing network growth while optimizing fracture conductivity," Journal of Canadian Petroleum Technology, vol. 48, no. 10, pp. 39-51, 2009.

[19] D. M. Jarvie, R. J. Hill, T. E. Ruble, and R. M. Pollastro, "Unconventional shale-gas systems: the Mississippian Barnett shale of north-central Texas as one model for thermogenic shale-gas assessment," AAPG Bulletin, vol. 91, no. 4, pp. 475-499, 2007.

[20] R. Rickman, M. J. Mullen, and J. E. Petre, "A practical use of shale petrophysics for stimulation design optimization: all shale plays are not clones of the Barnett shale," in SPE Annual Technical Conference and Exhibition, Society of Petroleum Engineers, 2008.

[21] X. Jin, S. N. Shah, J.-C. Roegiers, and B. Zhang, "Fracability evaluation in shale reservoirs-an integrated petrophysics and geomechanics approach," in SPE Hydraulic Fracturing Technology Conference, Society of Petroleum Engineers, 2014.

[22] W. Yu, Z. Luo, F. Javadpour, A. Varavei, and K. Sepehrnoori, "Sensitivity analysis of hydraulic fracture geometry in shale gas reservoirs," Journal of Petroleum Science and Engineering, vol. 113, pp. 1-7, 2014.

[23] G. E. King, "Thirty years of gas shale fracturing: what have we learned?," in In: SPE 133456, presented at the SPE Annual Technical Conference and Exhibition, pp. 19-22, Florence, Italy, 2010.

[24] L. K. Britt and J. Schoeffler, "The geomechanics of a shale play: what makes a shale prospective," in In: SPE 125525, presented at the 2009 SPE Eastem Regional Meeting, pp. 23-25, Charleston, West Virginia, 2009.

[25] T. Guo, S. Zhang, Z. Qu, T. Zhou, Y. Xiao, and J. Gao, “Experimental study of hydraulic fracturing for shale by stimulated reservoir volume," Fuel, vol. 128, pp. 373-380, 2014. 
[26] M. Y. Soliman, L. East, and J. Augustine, "Fracturing design aimed at enhancing fracture complexity," in In: SPE 130043, presented at the SPE EUROPEC/EAGE Annual Conference and Exhibition, pp. 14-17, Barcelona, Spain, 2010.

[27] Z. Chen, C. J. Xue, T. X. Jiang, and Y. M. Qing, "Proposals for the application of fracturing by stimulated reservoir volume (SRV) in shale gas wells in China," Nat Gas Ind, vol. 30, no. 10, pp. 30-32, 2010.

[28] V. Sesetty and A. Ghassemi, "A numerical study of sequential and simultaneous hydraulic fracturing in single and multilateral horizontal wells," Journal of Petroleum Science and Engineering, vol. 132, pp. 65-76, 2015.

[29] Q. Li, B. Lin, and C. Zhai, "The effect of pulse frequency on the fracture extension during hydraulic fracturing," Journal of Natural Gas Science and Engineering, vol. 21, pp. 296-303, 2014.

[30] A. Peirce and A. Bunger, "Interference fracturing: nonuniform distributions of perforation clusters that promote simultaneous growth of multiple hydraulic fractures," SPE Journal, vol. 20, no. 2, pp. 384-395, 2014.

[31] W. Yu and K. Sepehrnoori, "Optimization of multiple hydraulically fractured horizontal wells in unconventional gas reservoirs," Journal of Petroleum Engineering, vol. 2013, 2013.

[32] D. H. Shin and M. M. Sharma, "Factors controlling the simultaneous propagation of multiple competing fractures in a horizontal well," in SPE Hydraulic Fracturing Technology Conference, Society of Petroleum Engineers, 2014.

[33] C. Cai, Y. Kang, X. Wang et al., "Experimental study on shale fracturing enhancement by using multi-times pulse supercritical carbon dioxide $\left(\mathrm{SC}-\mathrm{CO}_{2}\right)$ jet," Journal of Petroleum Science and Engineering, vol. 178, pp. 948-963, 2019.

[34] S. Heng, X. Liu, X. Li, X. Zhang, and C. Yang, "Experimental and numerical study on the non-planar propagation of hydraulic fractures in shale," Journal of Petroleum Science and Engineering, vol. 179, pp. 410-426, 2019.

[35] B. Hou, R. Zhang, Y. Zeng, W. Fu, Y. Muhadasi, and M. Chen, "Analysis of hydraulic fracture initiation and propagation in deep shale formation with high horizontal stress difference," Journal of Petroleum Science and Engineering, vol. 170, pp. 231-243, 2018.

[36] A. Taghichian, M. Zaman, and D. Devegowda, "Stress shadow size and aperture of hydraulic fractures in unconventional shales," Journal of Petroleum Science and Engineering, vol. 124, pp. 209-221, 2014.

[37] O. Kresse, X. Weng, H. Gu, and R. Wu, "Numerical modeling of hydraulic fractures interaction in complex naturally fractured formations," Rock Mechanics and Rock Engineering, vol. 46, no. 3, pp. 555-568, 2013.

[38] H. J. Wang, D. A. Liu, and Z. D. Cui, "Investigation of the fracture modes of red sandstone using XFEM and acoustic emissions," Theoretical and Applied Fracture Mechanics, vol. 85, pp. 283-293, 2016.

[39] H. J. Wang, F. Zhao, and Z. Q. Huang, "Experimental study of mode-I fracture toughness for layered shale based on two ISRM-suggested methods," Rock Mechanics and Rock Engineering, vol. 50, no. 7, pp. 1933-1939, 2017.

[40] M. C. Zhou and Y. Jin, "Analysis of fracture propagation behavior and fracture geometry using a tri-axial fracturing system in naturally fractured reservoirs," International Journal of Rock Mechanics and Mining Sciences, vol. 45, no. 7, pp. 1143-1152, 2008.

[41] C. J. de Pater, M. P. Cleary, T. S. Quinn, D. T. Barr, D. E. Johnson, and L. Weijers, "Experimental verification of dimensional analysis for hydraulic fracturing," SPE Production \& Facilities, vol. 9, 1994. 